\title{
VILLA ET CASTIELLO DE ELLA (ELDA, ALICANTE) EN EL SIGLO XIII
}

\author{
A. M. Poveda Navarro \\ Museo de Elda
}

Con este título presentamos un trabajo que pretende ser una aproximación histórica de una población medieval, Ella (Elda), que testimonie el tipo de vicisitudes derivadas de la situación de una villa medieval en una zona de camino-frontera, como lo era el valle del río Vinalopó donde se ubica Elda.

Desde la prehistoria este valle era una ruta natural de primera magnitud, la via Hercúlea, denominada Augusta con los romanos. Tal ruta por su naturaleza fronteriza pudo ser fortificada con los visigodos y los bizantinos. Esta fortificación fue luego consolidada por los musulmanes, que construyeron una cadena de castillos o fortalezas en el valle del Vinalopó.

Esta frontera perduró hasta 1366, año de la división del Reino de Valencia en las gobernaciones de Ultra y Citra Xaxonam (1).

La importancia de dicha ruta, la mejor para penetrar desde el mar hacia la Meseta y Valencia, convirtió a una población ubicada en esa ruta en un lugar muy vulnerable a las circunstancias que afectasen a tal vía de comunicaciones.

Precisamente en el siglo XIII se dieron unas circunstancias que condicionaron la evolución de la villa de Elda (punto obligado de una ruta que todavia hoy está en vigor) y que son el objeto de estudio de este trabajo.

\section{INTRODUCCION}

La romanización de los iberos de la comarca de Elda condujo a la aparición de la ciudad romana de Ello en el Alto Imperio (la $A D E L L O$ del 
Itinerario de Antonino), que fue en época visigótica sede del obispado elotano (en la ELO del siglo VII) al que se refieren algunas actas de los Concilios de Toledo. La urbe se puede situar 1 kilómetro al norte de la actual ciudad, en el yacimiento denominado El Monastil, según es la opinión de diversos autores (2).

El valor político, religioso, económico y estratégico de la Elo hispanovisigoda debió influir para que esta ciudad fuese una de las afectadas por el Pacto de Teodomiro de Oriola, noble gardingo visigodo, con 'Abd-al'Azíz hijo de Muza, que se firmó en abril del año 713. La inclusión de la ciudad en este pacto habla en favor de su posible importancia dentro de la kúra de Tudmir.

La variabilidad de la grafía de los topónimos latinos al pasar a los textos árabes, ha llevado a que se confundiese Elo con otra ciudad de nombre y grafia árabe similares, que se lee lyih o lyyu(h) en los textos del pacto recogidos por Al-Dabbî y Al-`Udrī, e interpretados por Huici Miranda y Molina López (3). Para el primero tal ciudad estaría en las afueras de Hellín, para el segundo se ubicaria a $3 \mathrm{kms}$. al norte de la misma población. También Vilar se decide por Hellín (4), mientras Yelo Templado defiende su ubicación en las afueras de Cieza (5). Pero la reciente publicación de la versión de Al-Himyarî (6) y dos de sus interpretadores, nos ofrecen la auténtica grafía árabe de Elo, $A /(a) h(7)$ o $/(a) h(8)$.

Se termina de confirmar así que Elo-II(a)h/Al(a)h fue una de las ciudades que quedaron a cargo de Teodomiro, correspondiéndose con Ella, la actual Elda.

En los siglos IX y XII, dos fuentes latinas citan un doble topónimo, EDELLE y ELOE, respectivamente, del Anónimo de Ravenna y de la Geografía de Guido (9). Se trata de una alusión corrompida de AD ELLO y de ELO.

En ese mismo período las fuentes árabes sobre Elo enmudecen del todo, aunque indirectamente conocemos algunos hechos de ese momento por referencias a otros puntos de la vía del Vinalopó (Biar, Villena, Aspe y Elche), y en general del Sârq Al-Andalus, región a la que pertenecía.

En un itinerario del siglo $\mathrm{XI}$, recogido por $\mathrm{Al}-{ }^{-} U d r i ̄$, se citan algunos puntos de esa ruta del Vinalopó (10).

Sabemos que la comarca de Elda se vio afectada por las correrías de EI Cid, a finales del siglo XI (11), en época de debilidad musulmana representada por los reinos de Taifas, momento en el que Elda pertenecía bien a la Taifa de Denia, bien a la de Murcia. También hay noticias del paso de Alfonso I el Batallador por el valle del Vinalopó en 1125 (12). Este mismo lo volvieron a recorrer los almohades, especialmente tras la campaña de Huete, en 1172 (13), quienes al establecerse en el Levante edificaron muchas fortalezas a lo largo de todo el Vinalopó. 
Es reseñable el silencio documental que se dio entre el final del siglo $\mathrm{XX}$ y el XIII, que la arqueología también parece confirmar. Tal hecho ya fue reseñado por P. Guichard y por R. Azuar (14). El primero de los cuales opina que hubo una despoblación del área derivada de una crisis climática, epidemiológica y económica. Causas que no puede afirmarse ni refutarse en opinión del segundo.

Ya en el siglo XIII las fuentes cristianas ofrecen muchos datos, algunos sobre Elo-IIh/Alh, ahora denominada Ella (a veces Ecla o Etla) y luego Elda; denominaciones que aparecen patentes en los documentos que referiremos en las próximas páginas.

La gran importancia del valle del Vinalopó como ruta-frontera queda clara en la lista de pactos, que entre las Coronas de Castilla y de Aragón se negocian y firman desde el de Carrión (1141) hasta el de Almizra (1244).

La villa de Elda se vio directamente afectada por toda esta dinámica, ya que pertenecía al reino musulmán de Murcia y se ubicaba en la cuenca media del valle del Vinalopó.

Las villas, castillos, alquerías, etc., de esa comarca a la que pertenecía Elda parece ser que se hallaban jurisdiccionalmente regidas desde el hisn Bitrīr (Petrer) (15), en el que se ubicaría el qa'id de la zona. Esa posibilidad depende de si se acepta o no que el término hisn equivale a la sede del representante del poder central, y desde donde se ejercería la jurisdicción sobre las comunidades musulmanas de una zona, tal y como entiende el término Azuar (16).

Estas eran las circunstancias que existian en las visperas de la anexión castellana de Elda, y de la mayor parte de las comarcas del Vinalopó.

\section{LA CONQUISTA (ANEXION) CASTELLANA Y SUS REPERCUSIONES}

\section{La Anexión}

Mediante el pacto de Alcaraz firmado en 1243 por Muhammad Ibn Hūd, rey de Murcia, y Fernando III el Santo, rey de Castilla, se convertiría el primero en vasallo del segundo y se convertía el reino murciano en protectorado castellano.

Cuando el 1 de mayo de ese mismo año llegó a Murcia el infante don Alfonso para hacer efectivo el pacto, las ciudades del reino de Murcia adoptaron distintas posturas. Murcia y Crevillente capitularon de buen grado, pero la mayoría de las ciudades que dependían teóricamente del rey Ibn Hūd no aceptaron el vasallaje o protectorado castellano y se pusieron en rebeldía, es el caso de Lorca, Cartagena, Mula, Orihuela, Elche, Aledo, Ricote, Cieza, Alhama, etc. (17), que tuvieron que ser tomadas por las armas de don Alfonso. 
Ella (Elda) era una villa musulmana del reino de Murcia de la que no sabemos qué postura adoptó respecto al pacto de Alcaraz, de ahí que desconozcamos el trato, recibido de Castilla. Sabemos que una vez que fue tomada el infante don Alfonso concede, el 15 de abril de 1244, a Guillén el Alemán «el castiello de Ella con su villa por heredat... con todas sus pertenencias, haciendole (aquél) el pleito homenaje al rey y prometiendo hacer con él guerra y paz, moneda y que siempre pertenezca al señorio real» (18).

La legitimidad de que Elda perteneciese al área de conquista castellana se había conseguido previamente el 26 de marzo de 1244, por el Tratado de Almizra firmado entre Jaime I de Aragón y don Alfonso de Castilla, en el que con ligeras variaciones respecto del anterior pacto de Cazola (20 de marzo de 1179) se marcaba la frontera entre Aragón y Castilla, que iría desde Almizra hasta Villajoyosa pasando por Biar, CastaIla, Jijona y Relleu, poblaciones que le correspondieron a Aragón. Al sur de esta línea el territorio sería para Castilla: Villena, Sax, Elda, Petrer, La Mola, Aguas y Alicante (19).

Con el doble objeto de premiar a parientes, nobles, instituciones eclesiásticas $u$ Ordenes Militares, y asegurar el mantenimiento de las tierras conquistadas, el rey castellano realizó donadíos y repartimientos. De esta política surgió esa primera donación de Elda al noble Guillén el Alemán (1244) o la posterior de 1245 por la que el castillo de Elda pasaba a la Orden de Santiago, «...nos, don Pelay Perez... reçibimos el castiello de Ella...» (20). Don Pelayo Pérez Correa, maestre de la citada Orden, mantuvo el señorío sobre Elda entre 1245 y 1257.

El paso del castillo de Elda de manos de Guillén el Alemán a las de la Orden de Santiago lo conocemos por un documento dado en Ocaña, el 20 de enero de 1245. Guillén debió morir al poco de obtener el donadio de Elda lo cual es comunicado por un hermano y un sobrino a don Alfonso y el maestre Pelay Pérez. Como don Guillén murió sin descendencia y sus parientes deseaban regresar a Alemania se estableció un convenio con Ios mismos: «...reçibiemos (Pelay y su Orden de Santiago) el castiello de Ella de don Arnalt el Aleman et de su fiio Enrrique por don Guillem el Aleman, que lo dio a la nostra Orden por su alma...". Por contra la Orden facilitaba el regreso a su tierra de los parientes, entregándoles cuatro caballos, cinco acémilas y cierta cantidad, parte en dinero y parte en letras, mientras ellos firmaban escritura de renuncia a cualquier derecho que pudiera corresponderles sobre Elda por parte de don Guillén.

Eran estos momentos los de los inicios e intentos de la repoblación del reino de Murcia por los castellanos, que como ocurria en Elda chocaban con el predominio poblacional de la mayoría musulmana bajo el dominio de la minoría castellana.

Hasta principio del siglo XVII la población de Elda era mayoritariamente musulmana (mudéjar ahora y morisca después). Si a esta evidencia 
añadimos la ausencia de indicios de evacuaciones poblacionales musulmanas promovidas por los castellanos, y sumamos también la opinión de Del Estal de que en todo el reino de Murcia no se dio ni un solo caso de vaciamiento poblacional mudéjar (21), es lícito suponer que en Elda no se expulsó a sus moradores mudéjares.

En 1252 queda Elda ubicada en el límite noroeste del alfoz alfonsino de Alicante al ser ampliado por Alfonso X con las aldeas de Novelda, Aspe el viejo y Aspe el nuevo, Nompot, Agost, Busot y Aguas (22).

Del Estal no sólo acepta que estuvo ubicada Elda en el mencionado límite del alfoz alicantino; él piensa que pudo formar parte del mismo como ocurría con Petrer (23). Aunque es una posibilidad nosotros no podemos pronunciarnos afirmativa o negativamente con los datos documentales actuales.

El 4 de agosto de 1253 se dio en Uclés un documento por el que Pelayo Pérez Correa, maestre de la Orden de Santiago, con el consentimiento de ésta y del comendador de Segura, Pedro Fernández, hizo donación a Sancho Sánchez de Mazuelo y a su mujer doña María González, de la villa de Elda, con entradas, salidas, términos, río y pertenencias. A la muerte de ambos esposos, Elda retornaría a los dominios de los santiaguistas. Estos obtenian a cambio de Elda algunas heredades de Sancho Sánchez y su mujer: Caudete y su castillo, sus términos y pertenencias, y la torre de Pechín, con su cortijo y términos (24).

Tal trueque parece que no se llegó a efectuar, así el 13 de agosto de 1256, Sancho Sánchez de Mazuelo vendió a un caballero denominado Gregorio la villa y castillo de Caudete y la villa y castillo de Pechín. Además, un año después (14 de abril de 1257) el rey Alfonso rescató ya de la Orden de Santiago las villas de Elda, Callosa y Catral, que se intercambiaban por las de Aledo y Totana (25).

La repoblación se hacía difícil como ya hemos señalado, a ello coadyuvaba la escasez de castellanos que pudieran desplazarse y asentarse en el reino de Murcia, las emigraciones de mudéjares murcianos al reino musulmán de Granada y al norte de Africa (26). A esta problemática creada desde mediados del siglo XIII añadimos nosotros la emigración mudéjar interna. La existencia de comarcas mudéjares murcianas bajo el control de un ra'is y ostentadoras de una importante autonomía, caso de Crevillente, actuaba como un sistema de evasión, esas comarcas eran polos de atracción para aquellos otros lugares mudéjares en la órbita de una política repobladora castellana cada vez más agresiva. De modo que en estos momentos se desplazaban a esas comarcas "refugios" algunos mudéjares. Como se desprende de las quejas que en 1304 dirigía el magnate castellano don Juan Manuel al rey de Aragón, a propósito de un musulmán (recaudador de impuestos) huido del señorío de Elda y Novelda que se refugió en Crevillente (27). 
Hacia 1257, con la presencia del propio Alfonso $X$ en Murcia, se intensificó la penetración castellana intentando asegurar el hasta entonces precario dominio sobre el reino de Murcia. En ese año se producen importantes repartimientos en dicho reino otorgándose alguno de ellos a personas de alto rango, como es el caso del infante don Manuel (28). El 14 de abril de 1257 mediante privilegio rodado de Alfonso X se "hace donación a la Orden de Santiago y su maestre don Pelay Perez, de las villas de Aledo y Totana con todos sus derechos, excepto moneda y justicia que se reserva para él, a cambio de Elda, Callosa y Catral. "E estos lugares sobredichos (Aledo y Totana) les do por camio de Ella que di al inffante don Manuel, mio hermano..." (29). Ella (Elda) se constituía ahora en señorío de don Manuel, no al principio de tomar don Alfonso el reino de Murcia como creyó Cascales, que afirmó que aquél se retiró de Murcia dejando como Adelantado mayor y administrador del reino a su hermano don Manuel, dándole por juro de heredad las villas y castillos de Elche, Crevillente, Aspe, Chinosa, Monóvar, Elda y Novelda con su castillo de la Mola (30). Pedro Ibarra ofrece esta misma versión, pero citando sólo las tres primeras villas, las restantes son sustituidas por la denominación valle de Elda, afirma además que don Manuel nombró a su vez a Diag Sánchez de Bustamante como su teniente (31). Estando Alfonso $X$ en Sevilla el 25 de abril de 1262 ratificaba el cargo y las heredades a su hermano Manuel, citando los mismos lugares que P. Ibarra (32).

La rebelión de los mudéjares mu rcianos (1264-66) en contacto con los musulmanes granadinos y del norte de Africa, obligó a Alfonso $X$ a pedir ayuda a su suegro Jaime I de Aragón para sofocar el citado levantamiento (33).

En la pascua de 1265 Jaime I encomendó al infante don Pere que hiciera una correría por el reino de Murcia, en el que se internó quemando y talando «tota la horta d'Alacant, e Nompot e Agost, e puis tallà Elx e la Vall d'Ella e de Noetla, Villena e Asp, Petrer, ...» (34).

La sofocación del reino de Murcia se inició en otoño de ese mismo año. Al frente de la expedición iban Jaime I, los infantes Pere y Jaume y don Ramón de Moncada, quienes tomaron incruentamente a la mayoría de las villas y castillos. Un claro ejemplo lo tenemos en Villena desde donde el rey Jaime I se desplazó hasta Elda, acampando en las afueras de la población. Sus moradores mudéjares le enviaron emisarios suplicando que no se les hiciera daño, a cambio le obedecerian en todo (35).

El levantamiento en Elda y en todo el señorio de don Manuel obedecia al mal trato dispensado por éste y los castellanos hacia los mudéjares.

De igual forma se tomaron la mayoría del resto de las villas a sofocar: Petrer, Mompot, Alacant, etc. En febrero de 1266 capituló Murcia con lo cual acababa la rebelión. Jaime I comunicó el triunfo a Alfonso $X$ y le 
devolvió sus territorios murcianos, a la vez que entregaba también al infante don Manuel las villas y castillos de Elx, Vall d'Elda y de Novelda, Asp y Petrer, que eran de su señorío desde antes del levantamiento (36).

Ante la posibilidad de nuevas algaradas Jaime I estableció una tropa de vigilancia fronteriza en dos lineas: la de Alicante-Orihuela con setenta caballeros a las órdenes de Bernardo Arnau y Galcerán de Pinós; y la de Alicante-Villena con cien caballeros bajo las órdenes de Artal de Luna y Gimeno de Urrea (37). Los importantes castillos de esta última línea (la valiosa ruta-frontera del Vinalopó): Alicante, Aspe, la Mola, Elda, Petrer, Sax y Villena, quedarian atendidos por esa guarnición. Además, tras la nueva confirmación en el cargo de Adelantado al infante don Manuel, Alfonso $X$ hizo (1266) labrar las villas y castillos del reino con muy fuertes labores (38), de forma que tanto el castillo de Elda como el resto de los castillos fueron reforzados.

\section{La repoblación}

La auténtica y activa repoblación de las tierras alicantinas tuvo lugar en Alicante, Elche, Orihuela y Villena, la población musulmana continuó siendo mayoría exclusivista en las comarcas del Vinalopó y del Bajo Segura. La afirmación de que Elda ( $y$ Petrer, Monóvar, Novelda, Aspe, Crevillente, Albatera, Cox, Redován y Granja de Rocamora) no contaba con una sola familia cristiana es excesiva, hay que entenderla en el sentido de que apenas quedaban cristianos en el último siglo medieval (s. XV). Tal interpretación la podemos justificar por la adscripción de Elda al Obispado de Cartagena y al vicariato de Elche. De esta forma Elda contribuiría económicamente a ambas entidades eclesiásticas con la contrapartida de que las mismas cubririan las necesidades espirituales de los escasos, pero existentes, cristianos de Elda. Además, los pleitos y alzadas de los cristianos de esta villa debían ser vistos en Elche, y los fueros y alcaldes que juzgasen a los de Elda eran igualmente los pertenecientes a Elche (40).

Esta serie de disposiciones fueron dadas por don Manuel, señor de Elche y Elda entre otras posesiones de la cuenca del Vinalopó que estuvieron en sus manos en la segunda mitad del siglo XIII.

Dichas disposiciones revelan la existencia de una universitas o comunidad cristiana aunque fuese reducida, que ya estaria presente en la segunda mitad del siglo XIII. Buena prueba de ello es la pequeña comunidad de cristianos existente en Elda en 1401. Un documento dado en Elche el 8 de febrero de ese año informa de los casats cristianos viejos de las comarcas de Elda y de Elche. Elda aparece en el documento (41) como el núcleo cristiano más numeroso de la cuenca media del Vinalopó: 


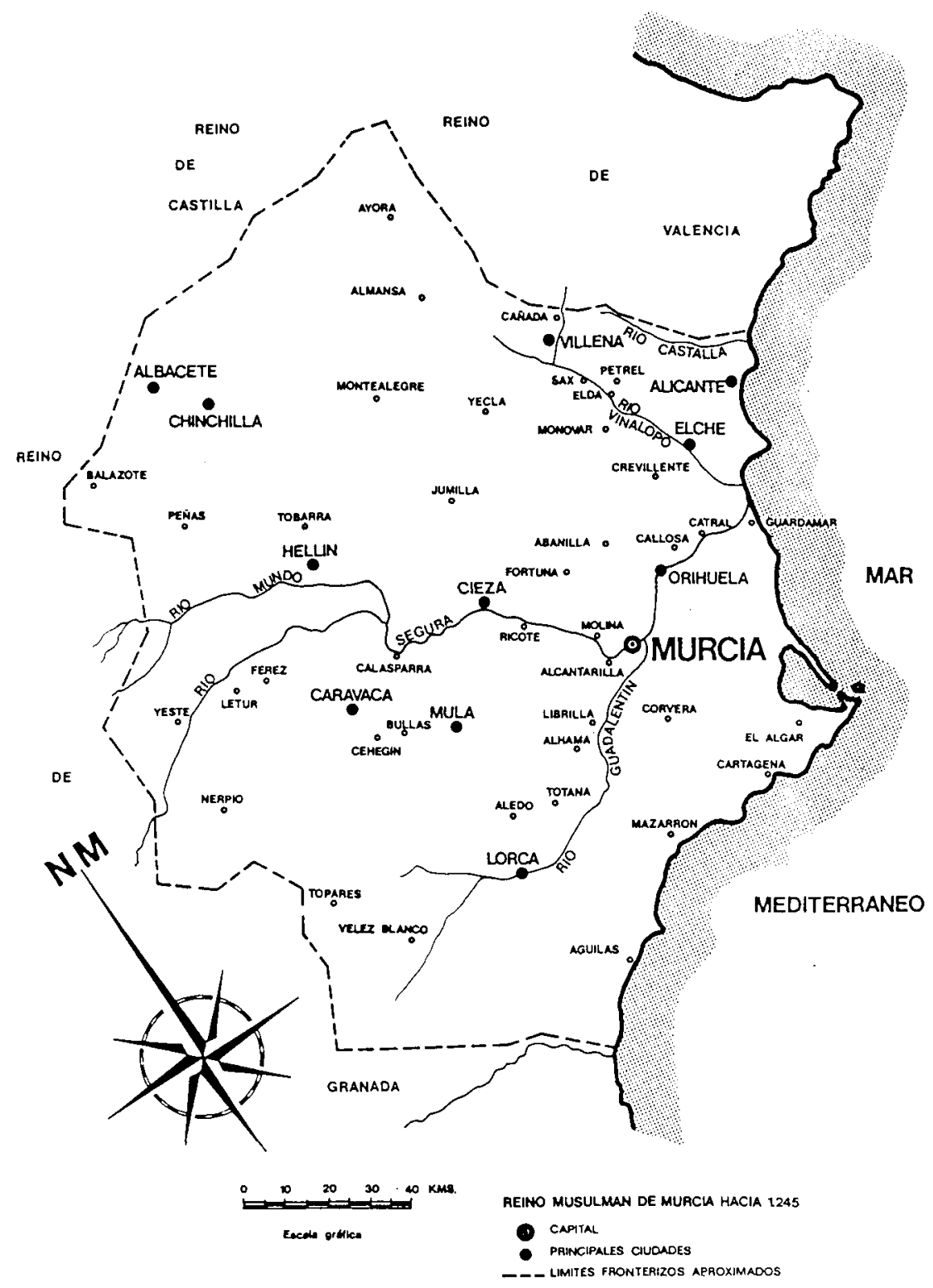

Gráfico 1

Situación de Elda en el noreste del Reino musulmán de Murcia (extraído de J. B. VILAR: Orihuela musulmana, Murcia, 1975). 


$\begin{array}{rrr}\text { Elda ....... } & 30 & \text { (casats, familias, } 4 \text { eran miserables) } \\ \text { Aspe....... } & 6 & \\ \text { Novella .... } & 11 & \text { (sumados los } 7 \text { de la Mola) } \\ \text { Montnover } & 2 & \\ \text { Petrer...... } & 4 & \\ \text { Salinas .... } & 8 & \\ \text { TOTAL } & 61 & \end{array}$

Según estos datos Elda contaba prácticamente con el cincuenta por ciento de los cristianos de su comarca. Sin embargo es un insignificante contingente si se compara con los 348 casats de Elche, lo que ascenderia a unos 1.600 habitantes cristianos (42). Si aplicamos la misma proporcionalidad casats/habitantes de Elche a Elda, los $30 \mathrm{ca}$ sats representarian un núcleo de unos 135 cristianos para esta última población.

Es evidente que la Elda de la segunda mitad del siglo XIII contaria con un número de cristianos mucho más pequeño que el de 135 .

La escasez de cristianos llegados a Elda explicaria el que los mudéjares no tuviesen necesidad de cambiar su ubicación en el interior de la villa, ni de formar una morería o barriada mudéjar al estilo de las formadas en Alicante, Elche y Orihuela, en la segunda parte del siglo XIII.

La morería de Elda debió formarse por todo el siglo XIV ya que en 1428 se dio el asalto de la misma (43). Cuatro años antes Ximén Pérez de Corella había adquirido el castillo y la villa de Elda, a la que llegó con un lógico grupo de cristianos (valencianos) que hicieron aumentar a la ya citada comunidad de 135 cristianos (1401). Este aumento de cristianos crearía tensiones de toda índole con la morería (44).

La comunidad cristiana aparece cada vez más clara hacia 1466 , cuando Elda obtiene la celebración de una feria anual mediante un documento en el que se cita a su universitati. Juan II concede la feria anual a Elda, a su «comiti (Joan Roiz de Corella), alcadio, veteribus, aliamis et universitati» (45).

A esta minoria cristiana hay que añadir la existencia de otra minoría como era la comunidad hebrea o judía. A comienzos del siglo XIV los judios de Elda entregaban al rey 100 sueldos anuales, mientras que los mudéjares pechaban 20.000 sueldos, doscientas veces la cifra cotizada por los judíos locales. Hacia 1300 Elda pechaba un cabezaje de 24.000 sueldos, incluidas pequeñas partidas no mudéjares (46). 20.000 sueldos procedían de los mudéjares, 100 de los judíos, el resto, 3.900 , procederían de la "universidad" de Elda.

Con estas cifras se puede intuir en qué proporción se distribuia el componente poblacional mudéjar, judío y cristiano, en la villa de Elda durante la Edad Media. 
En plena Edad Moderna (1597) existian en Elda 2.160 moriscos (47) y 360 cristianos (y en teoria ningún judío pues su comunidad fue expulsada en 1492). Si atendemos a esta inferioridad numérica cristiana respecto de la musulmana en este período, pensemos en una situación cristiana mucho más minoritaria en la segunda mitad del siglo XIII.

Los hitos básicos de la repoblación castellana de Elda (y de la Península Ibérica en general) se fundamentan en el establecimiento de una estructura administrativa eclesiástica y civil, en este caso concreto con sede en Elche, y en la pertenencia al señorío del infante don Manuel como auténtica figura repobladora de la época, en función de las inmensas propiedades que le cedió su hermano el rey Alfonso X: las comarcas de Villena, Elda, Novelda, Elche y Sta. Pola, constituian la gran propiedad de don Manuel. Esta y la de su hermano en el alfoz alicantino, suponían las mayores extensiones castellanas en la actual provincia de Alicante. Con ambas se pretendia implantar un auténtico dominio castellano al este del recientemente tomado reino de Murcia.

El proceso de implantar la citada estructura administrativa fue lento pero importante, como ahora constataremos en sus precisos pasos de desarrollo.

Comencemos por el terreno institucional eclesiástico. La Iglesia contaba con importantes hombres destacados en las tropas conquistadoras de Alfonso $X$, que recibian importantes lotes de tierra y que solían facilitar la implantación de la Iglesia en las nuevas tierras. Esta establecía pronto un sistema de beneficios eclesiásticos e importantes ingresos. Además creaba una dependencia institucional clave en la repoblación al constituirse obispados con sus respectivos vicariatos.

El 31 de julio de 1250 el Papa Inocencio IV consagraba como primer obispo del recién creado Obispado de Cartagena a Fray Pedro Gallego. Una vez que fue proclamado Alfonso $X$ como rey, dio contenido geográfico a dicho Obispado, dotándolo con «la villa de Alicante con su término, asi como partía con tierra del Rey de Aragón; y más Petrel, Sax y Villena y la tierra de don Manuel como partia con la tierra del Rey de Aragón;...». En esa tierra de don Manuel iba incluida Elda a quien le pertenecia desde 1257. Además, el Obispado se componia con varios vicariatos, en el de Elx se integraba su misma villa más Elda, Asp, Novelda, Salinas, Petrer, la Mola, Xinosa, Munover, Crevillent y el lugar de Asprella. En las villas y castillos de dichos lugares se erigieron iglesias y se instituyeron beneficios eclesiásticos (48).

En el Fundamentum Ecclesiae Cartaginense del obispo Nicolás de Aguilar (1366) se hace referencia a uno de los primeros prelados que atendieron Elda y otras villas de su comarca: «...Item, Petri Martini CalvieIlo, compositio maurorum, Elche et vallis de Elda et Novelda, Aspe, Chinosae et Monovar, quandiu duraverit et postea finita fuerit» (49). 
Los pocos cristianos existentes en las citadas poblaciones tendrian suficiente con el prelado Pedro Martini Calviello para satisfacer su vida espiritual, en el último tercio del siglo XIII.

Para reafirmar los términos del Obispado de Cartagena el rey Alfonso $X$ expidió un nuevo privilegio el 11 de diciembre de 1266: "Sepan cuantos este privilegio vieren y oyeren, como Nos, don Alfonso, rey de Castilla, que por saber que hemos de hacer bien y merced a don Fray Pedro, por la gracia de Dios obispo de Cartagena, a su cabildo y a todos sus sucesores, le otorgamos tenga este obispado los términos que tenía antes de la guerra que contra Nos promovió el rey de Granada; o sea Alicante con su término, lindante con Aragón; Petrel, Sax, Villena y la tierra de don Manuel, nuestro hermano, hasta los lindes del reino de Aragón» (50).

Después de concretar la dependencia de Elda respecto de Elche en materia de jurisdicción eclesiástica, don Manuel comenzó a legislar en el campo judicial.

Don Manuel estableció en Burgos, el 5 de abril de 1268, «... que todos Ios christianos de Elda que se iudguen poral fuero et por los alcaldes de Elche...» (51). Lo que significaba la dependencia también de Elche en materia de jurisdicción judicial.

Esta dependencia judicial era completada el 20 de diciembre de 1283, en Peñafiel, al ordenar don Manuel en su testamento «que las alzadas de los pleitos en los pueblos de Elda y Novelda, se vieran en Elche" (52). Además, en enero de 1270, Alfonso X «dá y otorga al Conceio de Elche, a los cristianos que y son pobladores agora e seran daqui adelante para siempre jamas, los fueros y franquezas que antes diera al Concejo de Murcia, población que disfrutaba los de Sevilla" (53). Lógicamente la villa de Elda se regiría igualmente por esos mismos fueros y franquezas merced a la ya citada orden dada por don Manuel en Burgos (5-IV-1268).

\section{Conquista y anexión de Elda a la Corona de Aragón}

En enero de 1284 moría don Manuel y dejaba sus señorios y lugares a su esposa doña Beatriz, que los regiria hasta la mayoría de edad de su hijo don Juan Manuel. Este se hizo cargo de la herencia cuando en 1292 moría Beatriz, pero tuvo que ceder las villas de Elda y Novelda con sus castillos a su hermana Violante Manuel, a la que le correspondían estas propiedades en virtud del testamento paterno (54).

Jaime II, rey de Aragón, apoyó en 1296 a los infantes de la Cerda aspirantes al trono de Castilla frente al nuevo rey castellano Fernando IV. Este hecho provocó la guerra entre ambas coronas.

El mayor de los infantes, don Alfonso de la Cerda, estimuló a Jaime II con el ofrecimiento de la soberanía de todos cuantos pueblos y castillos pudiera tomar en el territorio del reino de Murcia (que ya fue conquistado 
por su abuelo Jaime I pero en favor de Castilla en 1265-66, y al que no se resignaban a renunciar los aragoneses) (55).

Jaime II atacó Alicante por mar y por tierra hasta su conquista en 21-22 de abril de 1296. A continuación quedaría sitiada Elche.

Durante el sitio de Elche parte del ejército de Jaime II fue enviado a conquistar el valle de Elda y otras zonas del reino de Murcia (56). Anteriormente (20 de junio) Jaime Il había enviado una carta a doña Yolant (Violante Manuel) para que le reconociese soberano, pues de este modo conservaría Elda y Petrel (57).

La rendición de Elche, Sta. Pola, Aspe, Monóvar, Pinoso y Salinas, que negociaron don Juan Manuel, señor de estas villas, y Jaime ll cristalizaría en la tregua firmada por ambos sobre la base de que cuando don Juan Manuel alcanzase su mayoría de edad (21 años) habría de reconocer a Jaime II, "por señor y rey del reino de Murcia y él le mandaria entregar aquella villa y el puerto con los otros lugares» citados arriba, junto a «Elda $\checkmark$ Novelda y toda la otra tierra que don Joan Manuel tiene en el reino de Murcia» (58).

Dentro del pacto entre don Juan Manuel y Jaime ll ya citado existía una cláusula sobre Elda y Novelda a favor de doña Violante Manuel, hermana del primero y señora de estos lugares. Por lo que si deseaba conservar los castillos y los bienes de los mismos, debia reconocer también a Jaime II como rey de los territorios murcianos en disputa (59).

Con la tregua de siete años pactada entre los procuradores de don Juan Manuel (menor de edad) y Jaime II, en el sitio de Elche (27 de julio de 1296), se aseguraba a los hombres asentados en Chinosa, Monóvar, Salinas, Sta. Pola, Elda y Novelda (60).

Después de establecerse la cláusula referente a Elda y Novelda como señorío de doña Violante Manuel, Jaime Il expidió un documento que comunicaba a sus «procuratoribus, alcaidis, baiulis, iusticiis», etc., que los "sarracenos de Petrer et de Elda et de Novelda" los "recepimus sub nostra proteccione et guidatico speciali» (61).

En otro documento declara que esa protección no exime de pagar los tributos existentes al alcaide de los castillos de esos lugares, don Juan García de Loaysa, y alienta al uso de la coerción a sus oficiales en el caso de que se produzcan resistencias ante los cobros (62).

El 14 de mayo de 1303 enviaba Jaime II una carta a don Juan Manuel para prorrogar el pacto anteriormente establecido sobre Elda y Novelda. Los términos de la carta que nos interesan son los de «... alongamos el tiempo de la seguridad que fizimos de los logares de Elda e de Novelda contenido en las primeras posturas..., que cuando vos dicho noble don Johan cobraredes Elche e los otros lugares que avuedes en el regno sobreditos cobredes el derecho que avuedes o auer devedes en los ditos logares de Elda e de Novelda” (63). 
La guerra entre Fernando IV de Castilla y Jaime II de Aragón continuó hasta que en 1304 se reunió en Campillo un tribunal arbitral formado por, don Juan Manuel (Castilla), don Jimeno de Luna, Arzobispo de Zaragoza (Aragón) y don Dionis, rey de Portugal (arbitro) (64).

La sentencia arbitral se dio en Torrellas el 8 de agosto de 1304, expresando «que Cartagenia, Alacant, Elche con su puerto de mar e con todos los lugares que recuden a ell, Ella e Novella, Oriolla con todos sus términos e pertinencias, ...» pasaban a la Corona de Aragón (65). Con ella se realizaba el paso definitivo de Elda a la Corona de Aragón dentro del reino de Valencia.

Las razones del paso de territorios murcianos a la Corona de Aragón son dadas por el cronista Ramón Montaner. Jaime I habia entregado en dote a una hija a don Manuel que además recibia los territorios mudéjares de su propiedad, que tras una sublevación mudéjar fueron reconquistados por Jaime ! (1265-66). Pero como la hija de éste casada con don Manuel murió sin descendencia se debian «tornar al senyor rei d'Aragó,, los territorios citados. "E ara lo senyor rei d'Aragó volc-ho cobrar, e gran raon e dret que era; e aixi en aqueste paus recobrà-ho, co es: Alacant, Elx, Asp, Petrer, la Vall d'Etla e de Noetla, e la Mola, Crivileny, Favanella, Callosa, Oriola, Guardamar» (66).

El 13 de agosto Fernando IV y Jaime II se comprometian por carta a cumplir la sentencia arbitral (67).

Con el fin de hacer efectivo el traspaso de titularidad de Elda y el resto de las poblaciones citadas Jaime ll exigía a los alcaides de los castillos de las mismas, que entregaran éstos a su procurador don Gonzalo García. Doña Violante le entregó "los castillos e lugares de Ella e de Novelda" según se habia establecido en la sentencia (68).

A pesar de la demanda no se entregaron dichos lugares y castillos por lo que aparecieron tensiones entre los monarcas castellano y aragonés. Este hecho derivó en la constante emisión de cartas de protesta y demanda.

El 15 de noviembre de 1304 Jaime II reclamaba “... los lugares de Ella e de Novella e Elche, con sus terminos e pertenencias" (69).

La razón de la tardanza quedaba al margen de Fernando IV, que debía compensar al infante don Alfonso de Portugal y a su esposa doña Violante por la entrega de los territorios murcianos de ambos a Jaime II, de acuerdo con el pacto de Campillo. A cambio de las rentas de Elda y Novelda que dejaban de percibir, don Alfonso y doña Violante recibirían Medellín con sus términos, derechos y arroyo del puerto. Pero parece que no se veían suficientemente compensados en el cambio y por ello dilataban el traspaso.

En esta problemática es interesante conocer las rentas de Elda y Novelda, concretamente lo que pechaban anualmente al rey a principios 


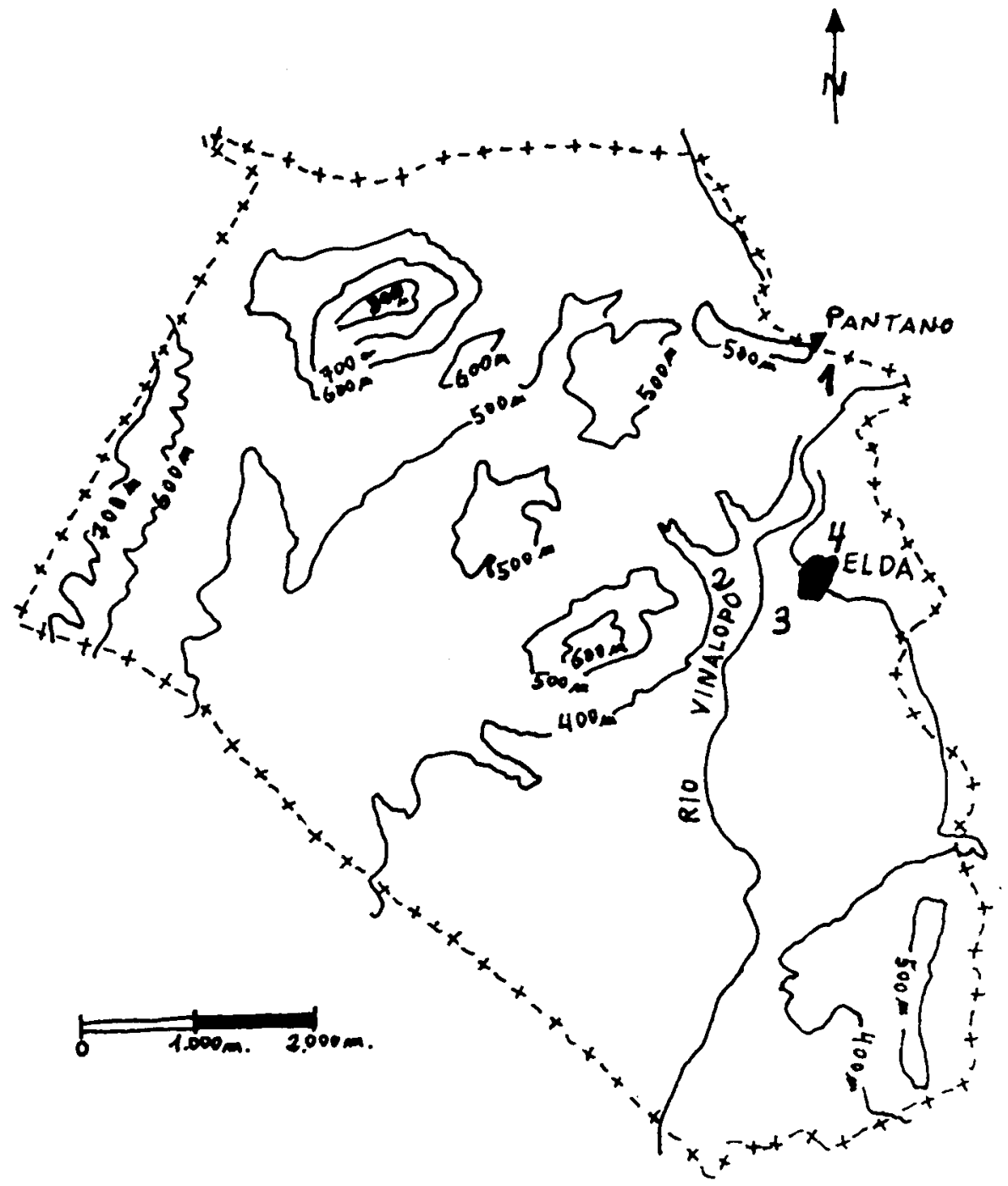

Gráfico 2

El término municipal de Elda con indicación de sus yacimientos arqueológicos musulmanes (ss. XII-XIII) y de su caso urbano:

1. El Monastil. 2. Laderas de Bolón. 3. Dos Puentes. 4. Casco urbano. 


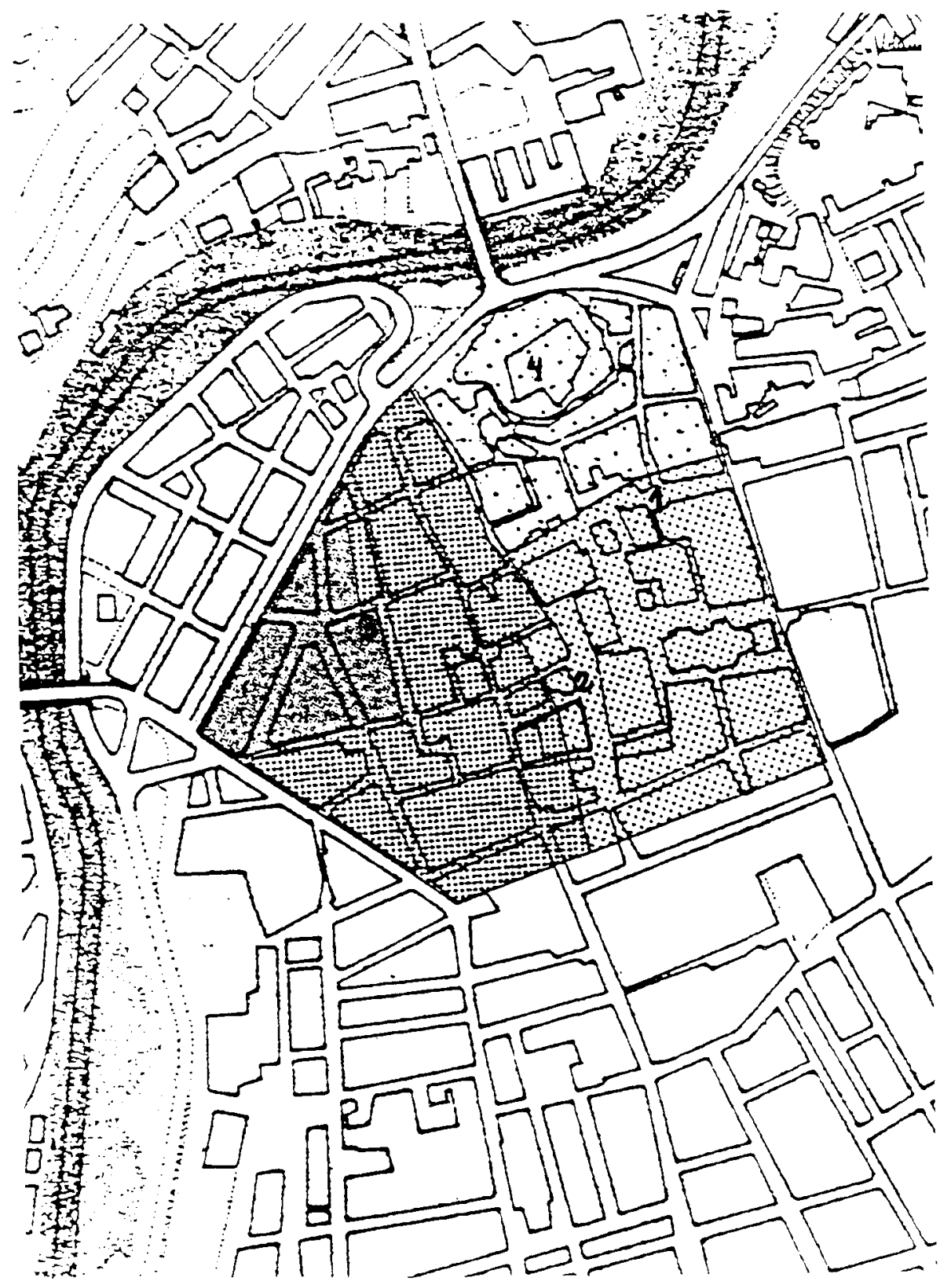

Gráfico 3

El núcleo urbano originario de la actual ciudad de Elda: evolución a partir de la zona del castillo y sus aledaños con mención de los restos arqueológicos musulmanes (ss. XII-XIII) más significativos:

1. Casa de J. Vidal y confluencia $\mathrm{c} /$ Ricardo León con $\mathrm{c} /$ Dos de Mayo. 2. Pza. Constitución. 3. c/ Gonzalo Sempere-c/ Huerto. 4. Castillo. 
del siglo XIV. Elda pechaba al rey 24.000 sueldos anuales (los gastos de tenencia del castillo en concepto de sueldo del alcaide y reparaciones ascendian al año 2.500 sueldos), mientras que Novelda pechaba 12.303 sueldos, en total 36.303 sueldos (70).

En febrero de 1305 Fernando IV afirmaba que los lugares que él entregaba en el cambio eran más valiosos y debian rentar más sueldos que los citados pechos de Elda y Novelda. Así se entiende que Fernando IV afirmase que los lugares que ofrecía «es cosa cierta que valen tanto y más que los dichos logares de helda y novelda...". Además protestaba y proponía como arbitro al arzobispo de Toledo, exigiendo que si «...valen mas estos logares que vos yo do por este canvyo que lo demas sea para $m i »(71)$.

Una carta del señor de Petrel y alcaide de los castillos de Elda y Novelda, pertenecientes a doña Violante, revela que su destinatario Jaime Il a causa de la tardanza pensaba tomar por las armas dichos castillos. Además ya no se menciona a Medellín en el cambio por Elda y Novelda sino a Carrión (72), que quizá complaciese más a don Alfonso de Portugal y su señora doña Violante Manuel.

Posteriormente el alcaide solicitaba una prórroga en la entrega de los castillos a lo que se negó Jaime li, que además dio ordenes a su consejero Gonzalo García para tomar los mismos, pero sin usar la fuerza (73).

Con el cambio de soberanía cesó el antiguo alcaide de los castillos del valle de Elda y Novelda, don Juan García de Loaysa, que fue sustituido por don Pedro de Montagut (74).

Una vez terminada la guerra y asegurado el cambio de soberanía en favor de Jaime Il de Aragón, éste tuvo que asumir los desperfectos ocasionados en dicha guerra, de modo que inició las restauraciones pertinentes en torres, castillos y murallas de Alicante, Elche, Orihuela, Villena, Petrel, etc... (75).

\section{LA INFORMACION ARQUEOLOGICA DE LA VILLA DEL SIGLO XIII}

Exponemos en este punto un sucinto resumen de los datos aportados por nuestro personal muestreo, sobre los materiales arqueológicos musulmanes del siglo XIII aparecidos en el término de Elda.

Hay que advertir que se trata de los datos de un primer muestreo por to que los mismos son provisionales. Futuros estudios arqueológicos confirmarán o refutarán, y en todo caso ampliarán, los datos que ahora avanzamos de un material hasta hoy prácticamente inédito (depositado en el Museo Arqueológico de Elda), generalmente recogido tras la destructiva labor de las palas de las máquinas excavadoras.

Los yacimientos a los que corresponden los materiales que nos interesan se distribuyen en dos ámbitos diferentes, la zona urbana y la zona rural. 
En el actual casco antiguo de Elda (ubicado al noroeste de la ciudad) hemos localizado tres puntos con restos arqueológicos de los siglos XII y XIII. Uno en las cercanias de la antigua casa de J. Vidal (lindando con el extremo oeste de la calle Dos de Mayo); otro en un solar de la Plaza de la Constitución (hacia el centro-sur del casco antiguo); y el tercero en un solar de la calle Gonzalo Sempere (en la confluencia con la del Huerto, en el limite oeste del casco antiguo).

En el límite norte de la ciudad medieval queda emplazado el castillo cuyos materiales más antiguos son también de los siglos XII-XIII, es decir, de época almohade y las décadas inmediatamente anteriores a la conquista cristiana.

Los materiales que nos han servido de guía (aunque existiesen otros) son especialmente las cerámicas de «cuerda seca», las esgrafiadas con pintura en manganeso y las estampilladas.

\section{a) Casa de J. Vidal c. Dos de Mayo}

En antiguas obras realizadas en su proximidad aparecieron restos arqueológicos de los que apenas quedan unos pocos fragmentos, entre ellos algunos de cuerda seca y de esgrafiado con pintura en manganeso.

En un solar que hace esquina entre la calle Dos de Mayo y la de Ricardo León se están realizando unas prospecciones arqueológicas que han exhumado restos de distintas épocas. En el momento de redactar este trabajo se excavaba un pozo que aportaba materiales cerámicos como las piezas esgrafiadas pintadas en manganeso y las estampilladas.

Ambos conjuntos arqueólogicos corresponden a la segunda parte del siglo XII o primera del XIII.

\section{b) Plaza de la Constitución}

En un pequeño solar se procedió recientemente a excavar en urgencia, apareciendo niveles arqueológicos modernos bajo los que se descubrió un pequeño murete, de piedra y barro, acompañado de escasos fragmentos esgrafiados y otros estampillados con igual técnica que la empleada sobre algunas piezas halladas en el castillo de Elda. Dichos fragmentos los datamos en los siglos XII-XIII.

\section{c) C. Gonzalo Sempere (antigua calle de La Tripa)}

Las obras de apertura de la cimentación de un nuevo edificio originaron el afloramiento en bolsadas de un ingente material musulmán (jarras, 


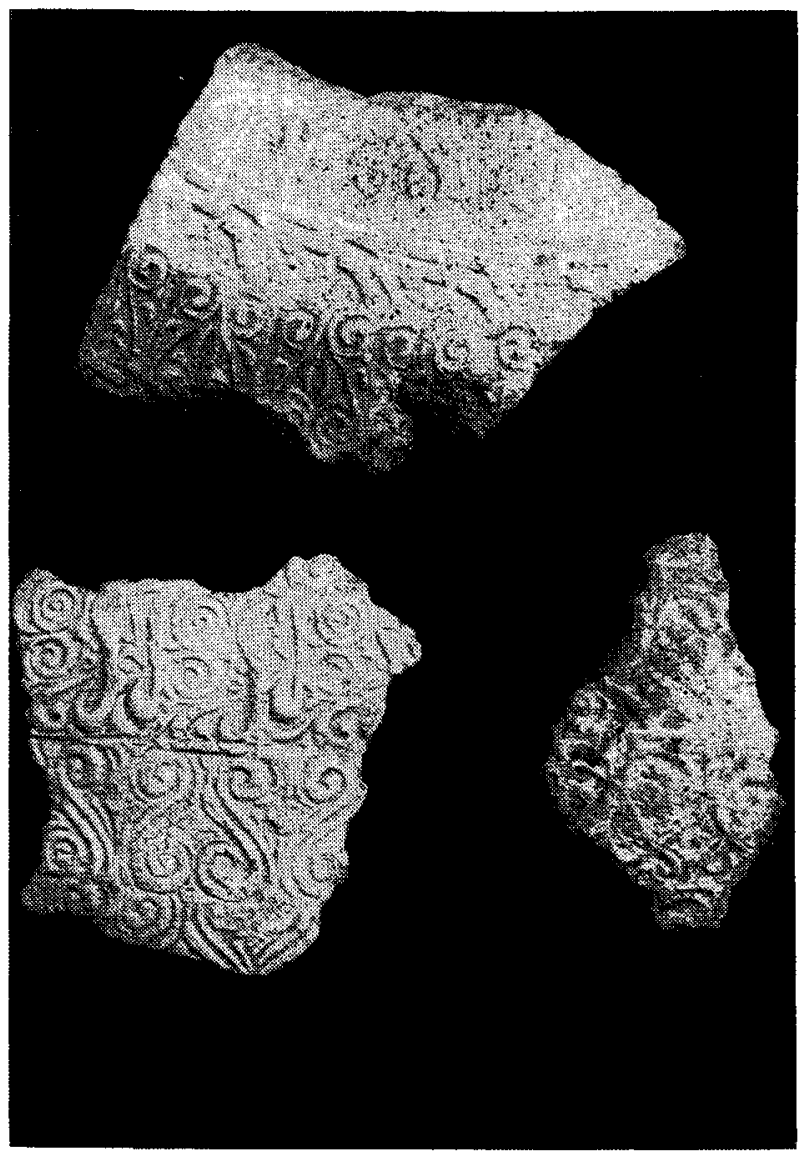

Foto 1

Cerámicas estampilladas del castillos de Elda.

marmitas, tapaderas, escudillas, cuencos, tinajas, etc...), del que destacan los fragmentos de cerámicas estampilladas y esgrafiadas. De las primeras debemos mencionar un fragmento que presenta como motivo estrellas de ocho puntas en cuyo interior se representan hojas vegetales. También es interesante el fragmento con arcos lobulados (foto 3). Pieza especial es un fragmento de una gran tapadera o brocal estampillado bellamente con motivos epigráficos, vegetales y geométricos. Además en su parte superior se observa parte de un texto esgrafiado (en escritura árabe cursiva) (foto 2).

Al margen de los materiales no se hallaron indicios de construcción alguna.

Como en el resto de los casos son materiales de los siglos XII-XIII. 


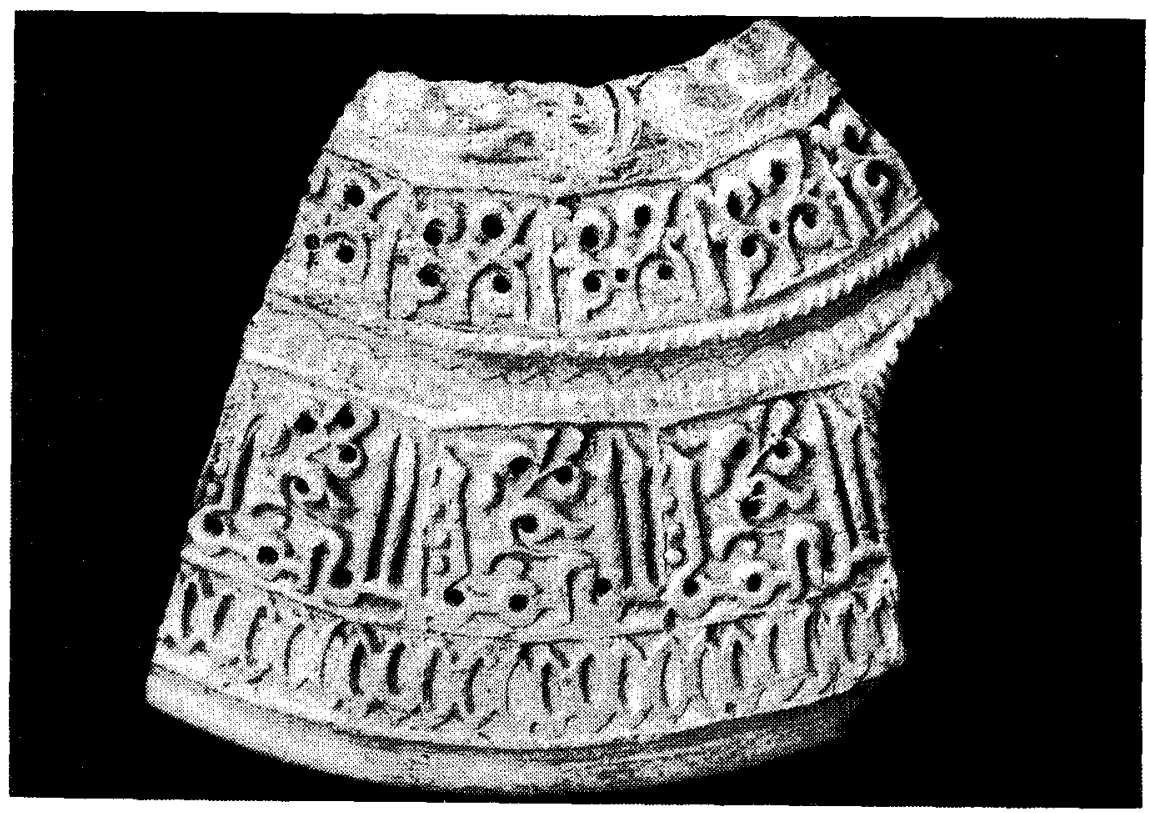

Foto 2

Fragmento de gran tapadera o brocal esgrafiado y estampillado (c/Gonzalo Sempere).

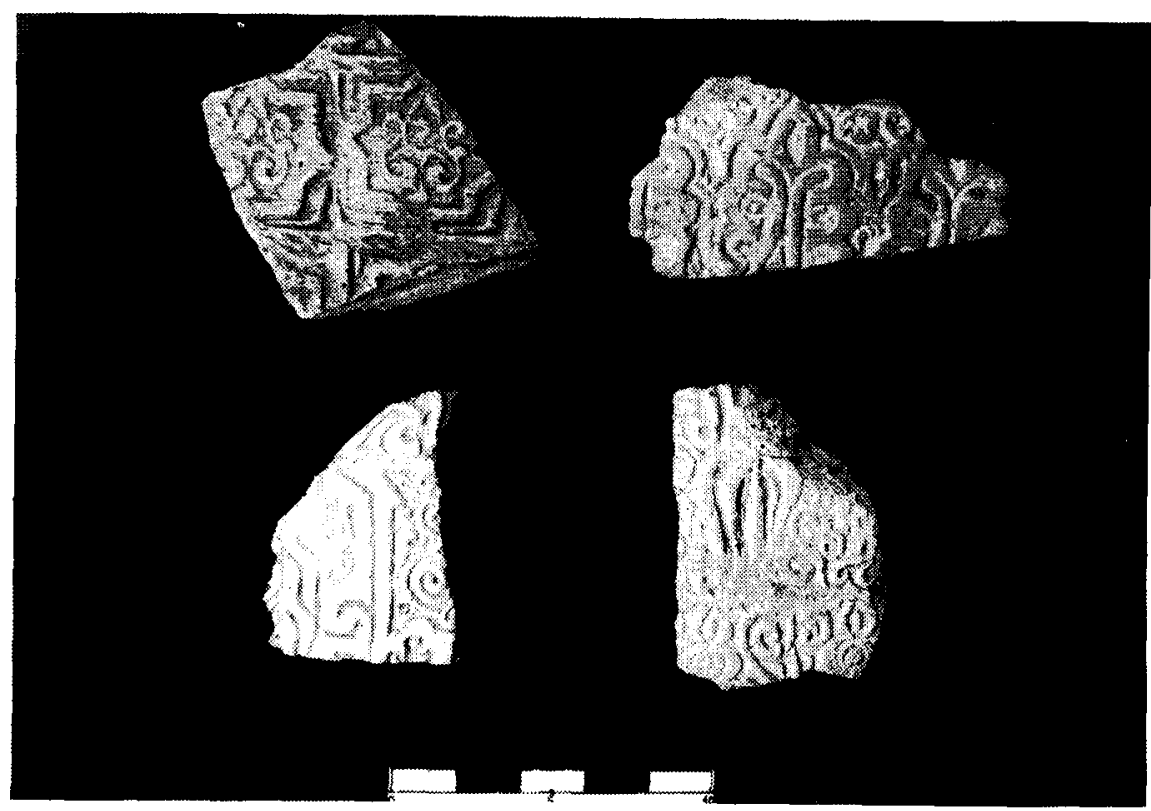

Foto 3

Fragmentos de cerámicas estampilladas (c/ Gonzalo Sempere). 


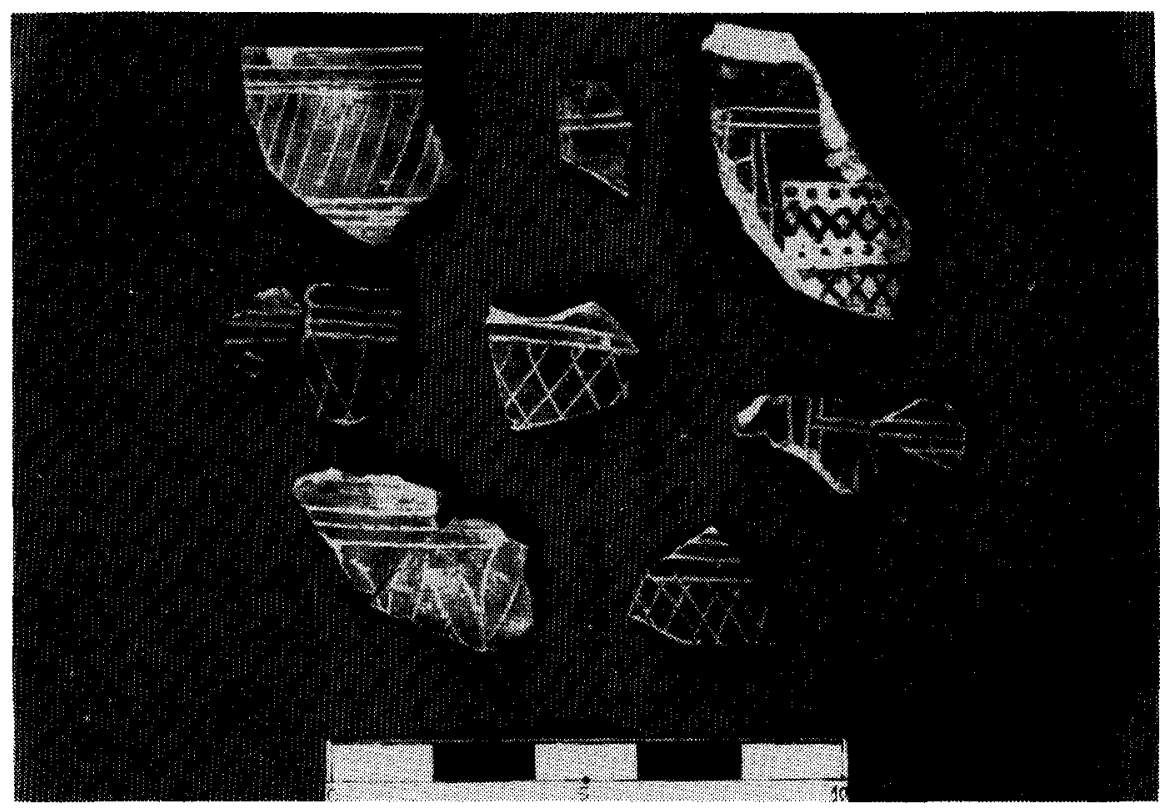

Foto 4

Cerámicas esgrafiadas con pintura en manganeso (c/ Gonzalo Sempere).

\section{d) Castillo de Elda}

Las excavaciones arqueológicas realizadas en un lateral del patio del castillo en 1983 aportaron abundantes materiales modernos y medievales. La cuadricula E-VI presentó una estratigrafía continuada desde el siglo XVIII hasta el XII. El último estrato, entre los 4 y 6 metros de profundidad, descansaba sobre la roca madre sobre la que se asienta el castillo, es el de su origen. Fue en él donde aparecieron las cerámicas más antiguas, cerámicas almohades de los siglos XII-XIII.

Al margen del vidrio y del metal hay que citar los fragmentos de cerámicas esgrafiadas, y especialmente los estampillados con motivos epigráficos, vegetales, geométricos, arquitectónicos y faunísticos.

La pieza más espectacular es una tinaja de la que se conservan numerosos y grandes fragmentos (fotos 5,6 y 7 ), que unidos lo mejor posible ofrecen una decoración distribuida en fajas o frisos. De arriba a bajo tenemos un primer friso con motivos epigráficos constituidos por texto árabe. Un segundo friso está decorado por arcos lobulados que terminan con una cúpula y que encierran representaciones animales, ciervos y quizá caballos; esta decoración parece ordenarse en metopas. El tercer friso contiene un nuevo texto árabe que se repite por todo el friso. El 
cuarto friso presenta grandes cúpulas entrelazadas. El quinto friso está ocupado por metopas que contienen alternativamente circulitos en espiral y gotas o lágrimas, motivos decorativos que completan y rellenan toda la tinaja como decoración secundaria. El sexto friso presenta las mismas cúpulas del cuarto, pero algo más reducidas. Hay restos de un séptimo friso, posiblemente el último, decorado con los mismos motivos del quinto. Todos los frisos aparecen separados por una estrecha banda con estrellas o asteriscos estampillados.

El mejor paralelo de esta pieza lo constituyen otras piezas semejantes aparecidas en la Casa Desbrull (Mallorca), que G. Rosselló data en época almohade (76).

Todos estos materiales, de finales del siglo XII y principios del XIII, aparecieron entre unas extrañas estructuras construidas a base de hiladas de grandes piedras que se alternaban con otras hiladas de tierra.

En otro sector del castillo apareció un dirhem almohade (foto 8 ), sin ceca ni mención de soberano y con este texto:

\section{Anverso: No (hay) Dios sino Allah Todo (es) para Aliah \\ Reverso: Allah (es) nuestro Señor No (hay) fuerza sino Allah \\ Mahoma (es) nuestro Enviado El Mahdi (es) nuestro Imán}

Se trata de un dirhem anónimo con una leyenda muy frecuente en este tipo de monedas (77). La ausencia de los signos de ceca y soberano se suele interpretar en un dirhem de esta clase como perteneciente a una ceca africana, aunque abundan las acuñaciones tardías e incluso fraudulentas (de reinos cristianos) (78) de tal tipo de dirhem de plata anónima. La moneda en cuestión hallada en el castillo puede fecharse en la primera parte del siglo XIII.

La información castellológica ratifica todo lo expuesto sobre el castillo de Elda y los materiales en él aparecidos.

La estructura antigua del castillo la formaban un recinto amurallado de forma poligonal, con enormes y macizos cubos en saliente de tapial de 1,35 por 0,90 metros, sobre basamentos de mampostería. En el interior del patio quedan restos de una construcción de tapial compacto, de planta rectangular y con tres ingresos adintelados, dos en su lado mayor y otro en el pequeño, en el lado oeste. Esta construcción la ha interpretado $R$. Azuar como la posible base de una torre (79).

Si conjugamos los datos históricos con los arqueológicos y castellológicos podemos suponer un origen para el castillo que remontaría hasta el último cuarto del siglo XII o principios del siglo XIII, que es una datación semejante a la propuesta por R. Azuar (80).

En el ámbito rural de Elda conocemos, de momento, la existencia de tres yacimientos con pruebas evidentes de una desigual actividad entre los siglos XII y XIII. Se trata de los yacimientos de EI Monastil, Dos Puentes y Laderas de Bolón. 

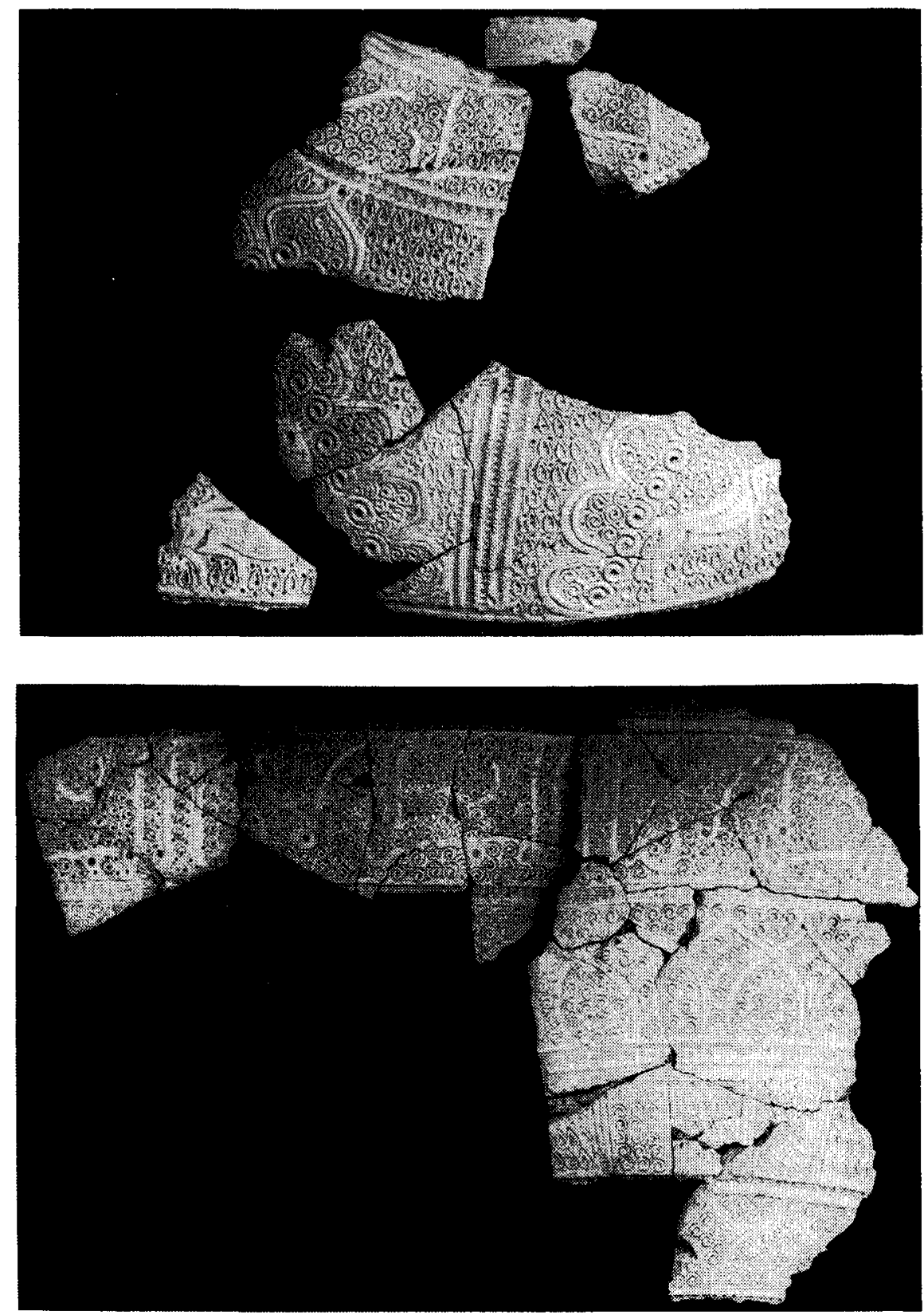

Fotos 5 y 6

Fragmentos de boca, hombro, panza y pared baja de una gran tinaja almohade estampillada con motivos epigráficos, arquitectónicos y faunísticos (Castillo de Elda). 


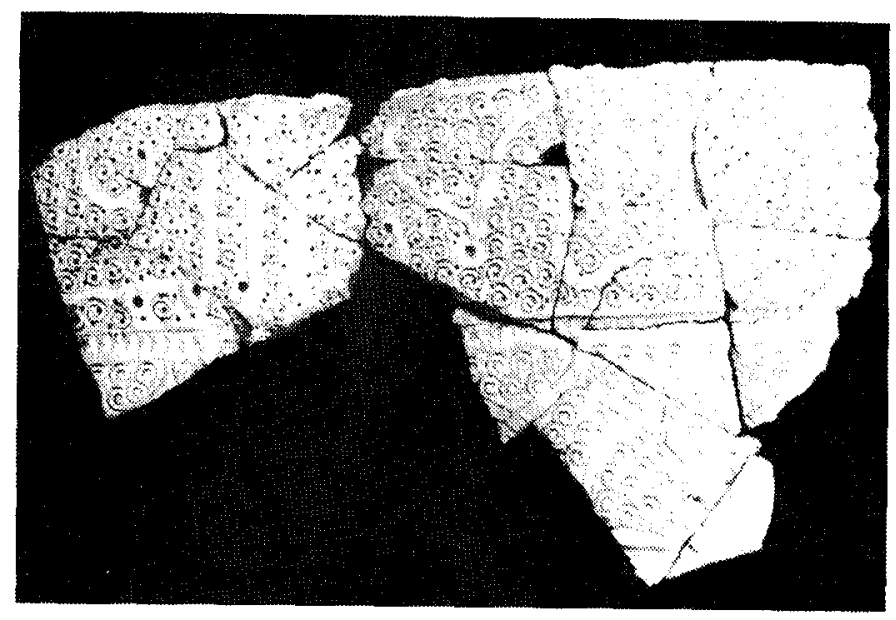

Foto 7

Detalle epigráfico de la anterior.
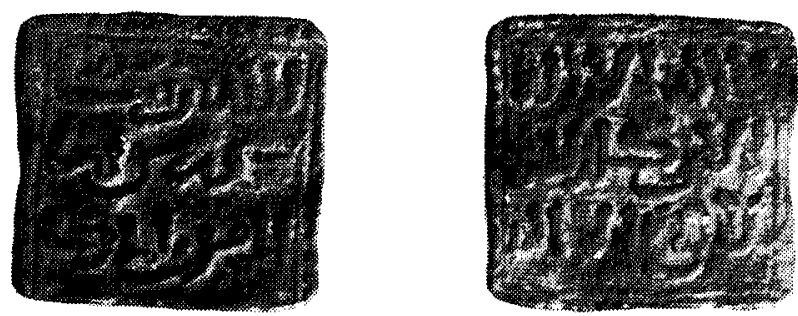

Foto 8

Anverso y reverso de un dirhem almohade anónimo (Castillo) (aumentado a 3 veces su tamaño). 


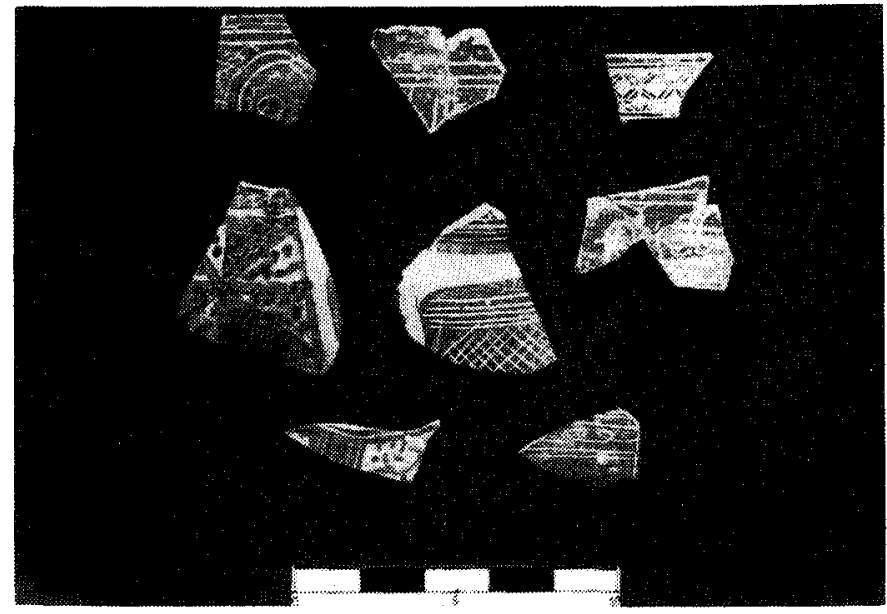

Foto 9

Cerámicas esgrafiadas pintadas en manganeso (Castillo).

\section{e) El Monastil}

Yacimiento situado $1 \mathrm{~km}$. al norte del casco urbano de Elda, en la estribación noreste del monte de La Torreta. En este lugar de habitat originado en el tránsito del Eneolítico al Bronce se ubica un poblado, que arranca de época ibérica y perdura hasta el fin del mundo romanovisigodo.

La arqueología tardorromana (81) del yacimiento ha propiciado las opiniones de Mateu i Llopis, Llobregat, Azuar y Poveda (82), que apuntan hacia la ubicación de la sede episcopal de Elo (la iglesia elotana) en El Monastil y su pervivencia hasta el siglo VII y el pacto de Teodomiro. Además, R. Azuar (83) no descarta la posibilidad de que se ubique en este poblado el al-Munastîr que cita Yāqūt en el siglo Xill, y que lo situaba en el este de al-Andalus.

La arqueologia constata la actividad humana en el poblado hasta el siglo VI, a partir del cual se produjo un hiatus hasta el siglo XII o XIII, momento al que pertenece un reducido lote de materiales entre los que se documenta un fragmento de cerámica esgrafiada pintada en manganeso, y otro de cuerda seca parcial y esgrafiado.

Tales materiales no tienen registro estratigráfico y corresponden a antiguas excavaciones.

\section{f) Dos Puentes}

Una reciente prospección realizada en la partida de esta denominación ubicada al sudoeste de la población, junto a la margen izquierda del 
río Vinalopó, ha aportado un lote de diversos materiales medievales (inéditos) de los cuales nos interesa mencionar la presencia de dos fragmentos de cerámica de cuerda seca junto a otros materiales.

Al margen de otros materiales más modernos, los citados y los que pertenecen a su mismo momento permiten afirmar la existencia de un posible asentamiento musulmán, de los siglos XII-XIII, que se asienta sobre una villa romana fechada momentáneamente entre los siglos I y III d.C.

\section{g) Laderas de Bolón}

Al oeste de Dos Puentes, en el otro lado del río, se ubica un importante despoblado musulmán indicio de la existencia de un poblado, o al menos una alqueria, hoy totalmente destruido.

El yacimiento estaba constituido por un área de construcciones y vertederos, otra área de galerias subterráneas, y una tercera con enterramientos en cistas construidas con losas.

Las construcciones estaban formadas por una serie de muros de piedras cogidas con argamasa (hoy desaparecidos a excepción de uno). Junto a dichas construcciones aparecian bolsadas de materiales cerámi$\cos$, destacando la presencia de algunos fragmentos de cerámica esgrafiada pintada en manganeso, y un fragmento del fondo de un ataifor vidriado de color amarillo con parte de dos estampillas (84). Pero la pieza más representativa y espectacular del yacimiento es una gran tinaja de dos asas, en parte restaurada, que presenta una técnica decorativa de relieves y estampillados epigráficos y arquitectónicos (fotos 10-11). La decoración se distribuye en cuatro frisos separados por dobles bandas (a veces triples) que presentan incisiones. El primer friso está decorado por un tex to árabe que se repite a lo largo de todo el friso. En este se implantan las asas. La decoración de los frisos segundo y tercero es a base de arcos de herradura musulmanes, que encadenados constituyen una arquería que recorre toda la panza de la tinaja. Un último y cuarto friso presenta una banda ondulada.

Este tipo de tinaja se ha documentado en otras áreas con una cronología mudéjar de los siglos XIII o XIV (85).

Además de las construcciones citadas conocemos un habitat en cuevas, del que pudimos excavar personalmente el conjunto denominado Galería de Jesús. Se trata de una galería excavada en la tierra, a 2,50 m. de profundidad del suelo actual. Tiene forma de pasillo en $L$ que alberga ocho cubículos para vivienda y almacén, igualmente excavados en la tierra. Los cubículos o cuevas eran semicirculares o casi circulares, con techumbre abovedada también excavada, con o sin pequeño pasillo de entrada que cuando existe es de medio cañón. En las paredes de las 
cuevas y del pasillo se excavaron también unos pequeños nichos para colocar en su interior las lucernas que iluminasen la galería.

La potencia estratigráfica es escasa dado el poco uso que debió tener este probable refugio subterráneo. Sin embargo, entre el escaso material hallado hay que reseñar una pequeña orcita vidriada y de barniz amarillo, y una lucerna de piquera del tipo III de G. Rosselló (86), del siglo XII, aunque el conjunto parece pertenecer al siglo XIII como el resto del yacimiento.

Al oeste del conjunto se ubica el Cerro de las Sepulturas, donde antaño aparecieron tres enterramientos en cistas de cuatro losas y una quinta superpuesta que las cierra. Además aparecieron otros restos humanos esparcidos por el cerro cortado por la erosión y la vía del ferrocarril (87).

No conocemos ajuar alguno que acompañase a los enterramientos que en opinión de R. Azuar serían tardorromanos (88), afirmación que nosotros no podemos apoyar ni refutar con los datos actuales.

Después de este somero análisis de la arqueología de Elda en los siglos XII y XIII podemos obtener unas primeras conclusiones.

Se verifica que la actividad y presencia musulmana aparece clara en la segunda parte del siglo XII y en el siglo XIII, en pleno período africano con los almohades.

Da la impresión de que en un primer momento los almohades se pudieron asentar en las afueras del pequeño núcleo de la villa de Elda, en la calle Gonzalo Sempere (fuera del Portal del Angel, puerta oeste de la villa medieval) y en el tramo Casa de J. Vidal y extremo oeste de la calle Dos de Mayo. También debieron darse unos primitivos asentamientos en torno al río Vinalopó, en Laderas de Bolón y Dos Puentes, y visitarian esporádicamente El Monastil. Estos asentamientos podrían ser un poco anteriores al asentamiento almohade del castillo, originado en este período.

Todos los asentamientos continuaron en siglos posteriores al XIII hasta englobarse en el casco antiguo de la actual Elda, sólo El Monastil y Laderas de Bolón finiquitan en el siglo XIII, lo que no es muy extraño pues se ubican en la zona rural.

El asentamiento almohade parece consolidar el crecimiento del núcleo medieval de Elda (villa y castillo) en el último cuarto del siglo XII. En plena evolución de esa villa llegó la "conquista" castellana de la misma, a mediados del siglo XIII (1243-44).

Cuando se presentan los almohades el pequeño núcleo medieval de la villa parece circunscribirse en el interior de un hipotético rombo irregular, con vértices en el castillo, calle Gonzalo Sempere, Plaza de la Constitución y en la intersección de la Casa de J. Vidal con la calle Dos de Mayo.

Con los actuales datos arqueológicos del siglo XIII parece confirmarse que no hubo expuisión de la población musulmana de Elda por parte de 

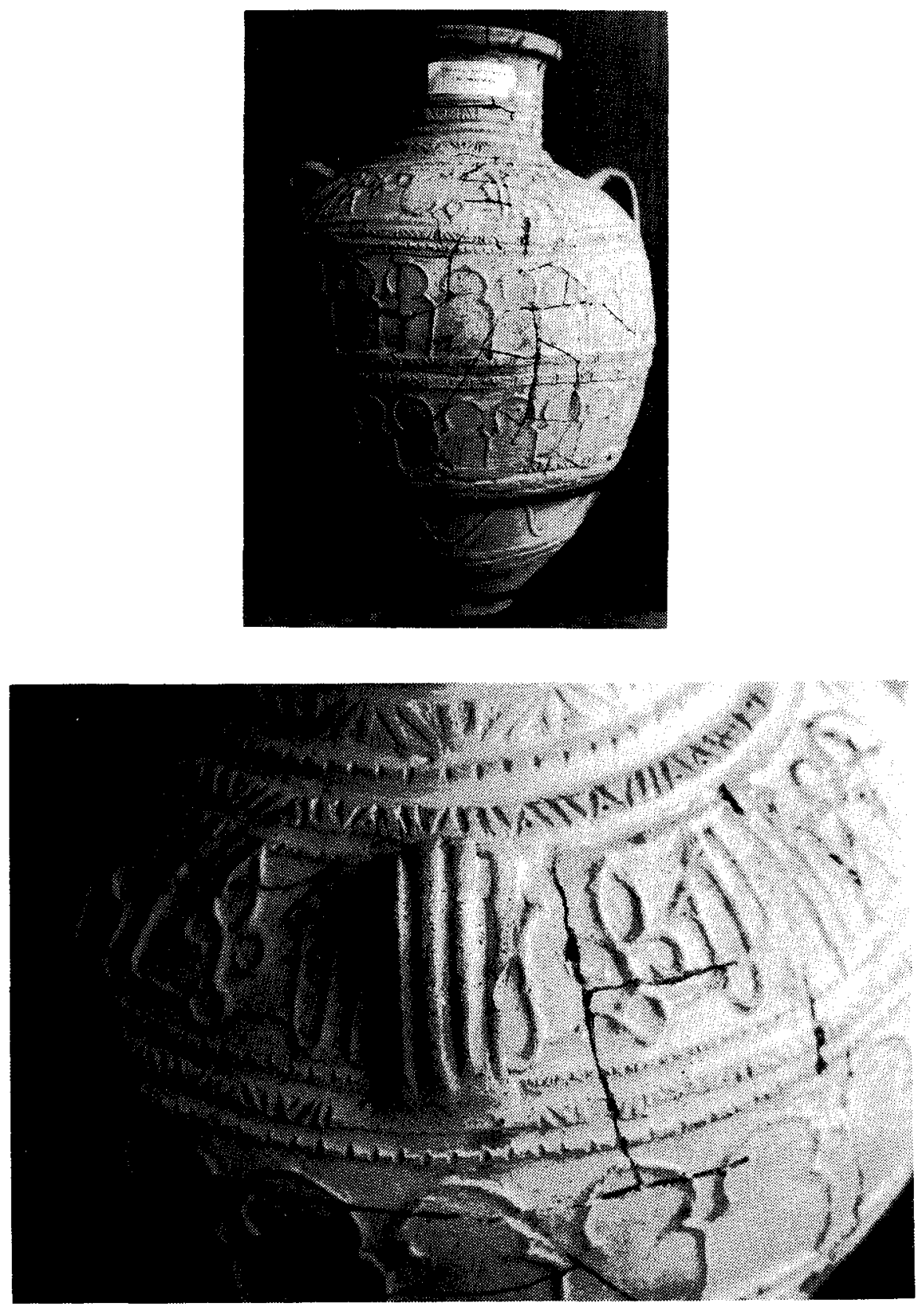

Fotos 10 y 11

Gran tinaja almohade estampillada y detalle de la misma (Laderas de Bolón). 
los castellanos que se hicieron cargo de la villa, a mediados del siglo XIII. Por ello no conocemos indicios de la formación de una morería extramuros de la ciudad. 


\section{NOTAS}

(1) E. A. LLOBREGAT, “Castillos y fronteras medievales en la provincia de Alicante", en Castillos de España, 70, 1970, pp. 130-32. J. B. VILAR, Los siglos XIV y XV. Historia de la ciudad de Orihuela, III, Murcia, 1977, pp. 278 ss. R. AZUAR, Castellologia Medieval Alicantina: Area Meridional, Alicante, 1981, p. 41; "Panorama de la arqueologia medieval en los valles alto y medio del Vinalopó (Alicante)", en Lucentum, II, Univ. de Alicante, Alicante, 1983, p. 350.

(2) F. MATEU I LLOPIS, "Sobre la identificación toponimica de Elota», en Homenaje a Millás Vallicrosa, II, Barcelona, 1956, pp. 31-39. E. A. LLOBREGAT, Teodomiro de Oriola, Caja de Ahorros Provincial de Alicante. Alicante, 1973, pp. 46-51; La primitiva Cristiandat Valenciana, L'Estel, Valencia, 1977, pp. 94 ss.; “Las sedes episcopales valencianas preislámicas y su dependencia metropolitana. Subsidios para un análisis de la Ordinatio Ecclesiae Valentinae", en Escritos del Vedat, X. Torrente (Valencia), 1980; Nuestra Historia, II, Valencia, 1980, pp. 178-9. R. AZUAR, Castellología Medieval..., op. cit., nota 1, p. 109; «Panorama de la Arqueologia Medieval...", op. cit. nota 1, p. 350. A. M. POVEDA, La Terra Sigillata de Elda (Alicante), Alicante, 1984, Memoria de Licenciatura presentada en la Universidad de Alicante (inédita); "La ciudad romana de Elo en época paleocristiana y su sede episcopal visigótica (ss. IV-VII). Estado de la cuestión", Alicante, 1984 (en prensa).

(3) F. CODERA-J. RIBERA editores de Al-Dabbî, Bugiat a/-multamis tîtârij rayâlahlal-Andalus, Bibliotheca Arabico Hispana, III, Madrid, Real Academia de la Historia, 1885. 'Abd-al'Aziz Al-Ahwāni editor de Al-`Udrî, Fragmentos históricos de almasalik ila yamica almamalik, Madrid, Instituto de Estudios Islámicos, 1965. A. HUICI, Historia musulmana de Valencia y su región, I, Valencia, 1970, p. 87. E. MOLINA, «La cora de Tudmir según al-cUdrí(s. XI)", en C.H.I., 4. Granada, 1972, p. 113; «Ultimas aportaciones al estudio de la Cora de Tudmir (Murcia). Precisiones y rectificaciones", en C.H.I., 7, Granada, 1975-76, pp. 83-111.

(4) J. B. VILAR, "La musulmana tyyu(h), Hellín actual», en Al-Basit, 3, Albacete, 1977, pp. $21-25$.

(5) A. YELO, "La ciudad episcopal de Ello", en Anales de la Universidad de Murcia, vol. XXXVII-1-2, Murcia, 1978-79, pp. 13-44.

(6) IHSAN ABBAS, editor de Al-Himyari, Kitab al-Rawd a/-Mictar fi Jabar al-Aqtar, El Cairo, Nasser Foundation for Culture, 1980.

(7) E. A. LLOBREGAT, "Relectura del Ravennate: dos calzadas, una mansión inexistente y otros datos de la Geografia antigua del País Valenciano", en Lucentum, II, Universidad de Alicante, Alicante, 1983, pp. 236-7.

(8) M. "JESUS RUBIERA, "Elda en el Pacto de Tudmir: camino y fortaleza", en Alborada, XXIX, Elda (Alicante), s/n.

(9) E. A. LLOBREGAT, «Relectura del Ravennate...», op. cit., nota 7, pp. 225-242. A. M. POVEDA, "La ciudad romana de Elo...", op. cit., nota 2.

(10) 'ABD-AL-'AZIA AL-AHWĀNI, Fragmentos geográfico-históricos..., op. cit., nota 3, p. 67. J. VALLVE, "La división territorial de la España Musulmana (II): La Cora de Tudmir", en Al-Andalus, XXXVII, 1972, p. 157. R. AZUAR, "Panorama de la Arqueología Medieval...», op. cit., nota 1, p. 351. 
(11) R. MENENDEZ PIDAL, La España del Cid, Madrid, 1969, p. 935. Crónica General de Ocampo, folio 321 v. R. AZUAR, «Panorama de la Arqueología Medieval...", op. cit., nota 1, p. 351.

(12) R. AZUAR, Castellologia Medieval..., op. cit., nota 1, p. 33.

(13) A. HUICl editor de Ibn Sāḥib Al-Salā, Al-Man bil-imāma, Valencia, 1969, p. 224. R. AZUAR, “Panorama de la Arqueologia Medieval...», op. cit., nota 1, p. 351.

(14) P. GUICHARD, «Le peuplement de la region de Valencia aux deux prèmiers siècles de la domination musulmane", en Melanges de la Casa Velázquez, V, Madrid, 1969, pp. 103-158. R. AZUAR, «Panorama de la Arqueologia Medieval...», op. cit., nota 1, p. 351.

(15) GAMAL 'ABD-AL-KARĪM, YĀQŪT. KITĀB MU'YÁM AL-BULDĀN, «La España musulmana en la obra de Yaqut (s. XII-XIII), repertorio enciclopédico de ciudades, castillos y lugares de Al-Andalus, extraidos del...", en C.H.I., 6, Granada, 1974, p. 108.

(16) R. AZUAR, «Una interpretación del 'ḩişn' musulmán en el ámbito rural», IDEA, 37, Alicante, 1982, pp. 33-34.

(17) P. GUICHARD, Un señor musulmán en la España cristiana: el Ra'is de Crevillente (1243-1318), Alicante, 1976, p. 16 (trad. S. Domenech). J. TORRES FONTES, “Murcia casteIlana», en Historia de la Región Murciana, III, Murcia, 1981, p. 297. J. M. DEL ESTAL, Conquista y anexión de las tierras de Alicante. Elche, Orihuela y Guardamar al Reino de Valencia por Jaime /l de Aragón (1296-1308), Caja de Ahorros Provincial de Alicante, Alicante, 1982, pp. 38-39; Documentos inéditos de Alfonso X el Sabio y del infante, su hijo Don Sancho, Alicante, 1984, pp. 14-16.

(18) A.H.N., Santiago, Uclés, 118-2. V. MARTINEZ MORELLA, Franquezas de Alfonso $X$ el Sabio a Alicante, Alicante, 1951, doc. 205. J. TORRES FONTES, Fueros de Alfonso el Sabio al Reino de Murcia, Murcia, 1973, V (CODOM III). A. NAVARRO, Historia de Elda, I, Caja de Ahorros Provincial de Alicante, Alicante, 1980, p. 97. A. HERRERO, «Toponimia premusulmana de Alicante a través de la documentación medieval», en Anales de la Universidad de Alicante. Historia Medieval, 3, Alicante, 1984, p. 30.

(19) A.C.A., Cartas en papel, n. 127. J. M. DEL ESTAL, "Conquista y anexión... ", en op. cit., nota 17, pp. 147-154.

(20) A.H.N. Sellos, 63/2. J. TORRES FONTES, Documentos del siglo XIII, Murcia, 1969 (CODOM II), doc. VI. A. HERRERO, «Toponimia premusulmana...», op. cit., nota 18, p. 30.

(21) J. M. DEL ESTAL, Documentos inéditos de Alfonso X..., op. cit., nota 17, pp. 17-18.

(22) A.M.A. Arm. 1, lib. 3, fols. 298v-299r. J. M. DEL ESTAL, "Carta de Alfonso X el Sabio fijando el término municipal de Alicante", en Idealidad, 2, Alicante, 1976, facsímil, transcripción y comentario; “Delimitación del término municipal de la villa de Alicante por Alfonso Xel Sabio y Jaime II de Aragón (1252-1296)", en ITEM, 1, Alicante, 1976, pp. 96-109; Conquista y anexión..., op. cit., nota 17, pp. 63-66, 315-318; Documentos inéditos de Alfonso X..., op. cit., nota 17, pp. 20-27. Varios, Libro de los primitivios Privilegios de Alfonso $X$ el Sabio a Alicante. Estudio histórico y transcripción, ed. facsímil EDILAN, Madrid, 1984.

(23) J. M. DEL ESTAL, Documentos inéditos de Alfonso X..., op. cit., nota 17, pp. 20, 42 , mapas de las pp. 13, 21 y 43 .

(24) J. LOPEZ, Bullarium equestris ordinis S. Jacobi de Spatha, M. 1719, p. 189. J. TORRES FONTES, Documentos del siglo XIII, op. cit., nota 20, doc. XVII. J. M. SOLER, «Historia de Villena", en Rev. Municipal Villena, Villena (Alicante), 1983, p. 97.

(25) J. M. SOLER, "Historia de Villena», op. cit., nota 24, p. 97.

(26) S. DE MOXO, Repoblación y Sociedad en la España Cristiana Medieval, Ed. Rialp. Madrid, 1979, p. 371.

(27) A. GIMENEZ, Don Juan Manuel, Zaragoza, 1932, pp. 307-308, doc. CV (31 de octubre 1304). P. GUICHARD, Un señor musulmán..., op. cit., nota 17, p. 29.

(28) S. DE MOXO, Repoblación y Sociedad..., op. cit., nota 26, pp. 373-4, 379

(29) A.H.N. Aledo, 50-2. V. MARTINEZ MORELLA, Franquezas de Alfonso $X$..., op. cit., nota 18, doc. 206. J. TORRES FONTES, Fueros de Alfonso X..., op. cit., nota 18, doc. XXXII. A. NAVARRO, Historia de Elda, op. cit., nota 18, p. 98. A. HERRERO, “Toponimia premusulmana...", op. cit., nota 18, p. 30 .

(30) F. CASCALES, Discursos históricos de la muy noble y muy leal ciudad de Murcia, Murcia, 1621 (reimpr. 1874 y 1980, Murcia), Discurso I, Capítulo XII.

(31) P. IBARRA, Historia de Elche, Alicante, 1895 (reimpr. facs. Valencia, 1982), p. 37.

(32) A. BALLESTEROS, Alfonso $X$ el Sabio, Barcelona, 1963, p. 346. J. TORRES FONTES, Fueros de Alfonso $X .$. , op. cit., nota 18 , doc. LXII.

(33) R. MUNTANEH, Xil, 677, en Les quatre grans croniques, F. Soldevila, Barcelona, 1971 
(34) R. MUNTANER, XIII, 678, op. cit., nota 33.

(35) Jaume I, 413, 150, op. cit., nota 33.

(36) R. MUNTANER, XVII, 681, op. cit., nota 33.

(37) R. COLOMA, La reconquista en tierras de Alicante, Caja de Ahorros de Alicante y Murcia, Alcoy (Alicante), 1976, p. 60.

(38) F. CASCALES, Discursos históricos..., op. cit., nota 30, Disc. II, Cap. IV. E. ABAD, EI castillo de la Mola de la ciudad de Novelda, Murcia, 1928, p. 60.

(39) S. SOBREQUES, Historia de España y América, II, Ed. Vicens Vives, Barcelona, 1961, p. 42. J. M. SALRACH, Historia dels Països Catalans, I, Ed. Edhasa, Barcelona, 1981, p. 603.

(40) D. DE SOMONTES, Ayuntamientos Manuscritos, I, fol. 169 ss. «Fundamentum Eciesiae Cartaginensis", 1450. J. PEREZ RICO, Notas Criticas para una Historia de Monóvar y de algunos de sus pueblos limitrofes, Ayuntamiento de Monóvar, Monóvar (Alicante), 1960, pp. 4-5. G. VIDAL TUR, Un obispado español: el de Orihuela-Alicante, Alicante, 1961, pp. 29-30. P. HERRERO, Aproximación a la Historia de Novelda, Novelda (Alicante), 1978, p. 10. A. IBARRA, IIIici, Alicante, 1879, p. 46. P. IBARRA, Historia de Elche, op. cit., nota 31, 31, pp. 58 y 105 . J. TORRES FONTES, Documentos del siglo XIII, op. cit, nota 20, docs. XXXVI (A.M.E., "Libro de privilegios", fol. XIV) y LXXX. A. NAVARRO, Historia de Elda, op. cit., nota 18, pp. 100-101.

(41) A.M.E. Llibre de Concells, n. 1 (antiguo 696), 8-III-1401. V. GOZALVEZ, La ciludad de Elche. Estudio Geográfico, Facultad de Filosofía y Letras, Valencia, 1976, p. 195.

(42) V. GOZALVEZ, La ciudad de Elche, op. cit., nota 41, p. 195.

(43) J. M. SALRACH, Historia de Països Catalans, op. cit., nota 39, p. 605. A. M. POVEDA "Elda y la familia de los Corella (s. XV)", en Alborada, XXIX, Elda (Alicante), 1983, s/p.

(44) A.C.A. Reg. 2.920, fol. 102. A. M. POVEDA, "Elda y la familia...", op. cit., nota 43.

(45) A.R.V. Real Cancilleria, vol. 289, fol. 75. M. RUZAFA, "El mercado y la feria de Elda en el siglo XV», en Alborada, XXX, Elda (Alicante), 1984, pp. 38-39.

(46) CODOIN AGCA, XXXIX, Rentas de la antigua Corona de Aragón, Barcelona, 1871, pp. 121-123. J. B. VILAR, Los ss. XIV-XV, op. cit, nota 1, pp. 51 y 56 . En la baylia de Orihuela se citan varias comunidades hebreas, la de Elda y las más importantes de Orihuela y Elche, que pechaban con 500 sueldos anuales. Es probable que también en el lugar de Petrer, situado junto a Elda, existiese algún elemento judio según se desprende de que al ilegar Jaime I a Elda (1265) recibiese a tres emisarios de Petrer, dos musulmanes y un judio (posiblemente emigrante de Castilla) (Jaume I, 414, 151, op. cit., nota 33; R. I. BURNS, Jaume $/ i$ els valencians del s. XIII, Valencia, 1981, p. 319).

(47) J. MARTINEZ VALLS, «Los moriscos de la diócesis de Orihuela a finales del siglo XVI», en Anales de Derecho, 1, Universidad de Alicante, Alicante, 1982, p. 258.

(48) D. DE ÇOMONTES, Apuntamientos Manuscritos, op. cit., nota 40. J. PEREZ RICO Notas criticas..., op. cit., nota 40. P. HERRERO, Aproximación..., op. cit., nota 40.

(49) P. HERRERO, Aproximación..., op. cit., nota 40.

(50) G. VIDAL TUR, Un obispado español, op. cit., nota 40. A. NAVARRO, Historia de Elda, op. cit., nota 18, p. 100.

(51) A. IBARRA, IIIici, op. cit., nota 40, p. 46. P. IBARRA, Historia de Elche, op. cit., nota 31, p. 105. J. TORRES FONTES, Documentos del siglo XIII, op. cit., nota 20 , doc. XXXVI. A. NAVARRO, Historia de Elda, op. cit., nota 18, p. 101. A. HERRERO, “Toponimia premusulmana...", op. cit., nota 18, p. 30.

(52) P. IBARRA, Historia de Elche, op. cit., nota 31, p. 58. A. NAVARRO, Historia de Elda, op. cit., nota 18, p. 101.

(53) P. IBARRA, Historia de Elche, op. cit., nota 31, p. 46.

(54) J. M. SOLER, La relación de Villena de 1572, Alicante, 1969, p. 91.

(55) J. M. DEL ESTAL, Conquista y anexión..., op. cit., nota 17, pp. 154-155.

(56) R. MUNTANER, CLXXXVIII, 835, op. cit., nota 33: «...E dins aquell temps que el setge se tenia, hac tota la vall d'Etla e de Noetla, e Nompot, Asp, Petrer, la Mola. E hac Criveleny, que l'arris de Creveleny se'n ven a ell e es feu son hom e son vassall. E puis hac Favanella, Callosa e Guardamar». J. ZURITA, Anales de la Corona de Aragón, V, XXI, Zaragoza, 1569-71, p. 500. J. M. DEL ESTAL, Conquista y anexión..., op. cit., nota 17, p. 169.

(57) A.C.A. Reg. 340, fol. 148v. J. M. DEL ESTAL, Conquista y anexion..., op. cit., nota 17 , pp. $349 ; 350$. Esta carta fue precedida de otra enviada por Jaime li a don Alfonso de Portugal (esposo de Violante Manuel y hermano del rey portugués don Dionis), en la fecha del 28 de abril de 1296. El primero pide que las villas que posee la esposa del segundo en el reino de Murcia, caso de Elda y Novelda, le reconozcan como soberano, pues de lo contrario iria contra ellas. Al final se aceptó el reconocimiento de la soberanía de Jaime II sobre esas villas y los territorios 
murcianos tomados por él (A.C.A. Reg. 340, fol. 52v. J. M. DEL ESTAL, Conquista y anexión..., op. cit., nota 17, pp. 202-3 y 251).

(58) E. ABAD, El castillo de la Mola, op. cit., nota 38, p. 68. J. ZURITA, Anales..., op. cit., nota $56, \mathrm{pp} .500-1$.

(59) A.C.A. Reg. 340 , fols. $156 \mathrm{v}$ y y 157; Reg. 292 , fols. $1 \mathrm{v}$. y 2 . Conventionum et Dotum Reginarum Jacobi II: "E como nos ya ayamos assegurado por amor de don Johan e dona Yolant su ermana por razon de los buenos deudos que an con nos los logares de Elda e de Novelda, aun los asseguramos assi como a toda la otra tierra del dicho don Johan que a en el regno de Murcia...". E. ABAD, El castillo de la Mola, op. cit., nota 38, p. 69. A. NAVARRO, Historia de Elda, op. cit., nota 18, pp. 103-4.

(60) A.C.V. perg. 567. J. M. DEL ESTAL, Conquista y anexión, op. cit., nota 17, pp. 264-5.

(61) A.C.A. Reg. 340 , fol. 122. E. ABAD, El castillo de la Mola, op. cit., nota 38, p. 69, doc. 3. A. NAVARRO, Historia de Elda, op. cit., nota 18, p. 103.

(62) A.C.A. Reg. 340, fol. 157. E. ABAD, ibid., pp. 69-70. A. NAVARRO, ibid., pp. 103-4.

(63) A.C.A. Reg. 292, fol. 17v. E. ABAD, ibid., p. 69, doc. 2. A. NAVARRO, ibid., p. 105.

(64) J. ZURITA, Anales..., op. cit., nota 56, V, LXVI, p. 667.

(65) A.C.A. Legajos de pergaminos del año 1304, agosto, N. ${ }^{\circ} 66$. E. ABAD, El castillo de la Mola, op. cit., nota 38, p. 74, doc. 5. J. M. DEL ESTAL, Conquista y anexión, op. cit., nota 17 , p. 177 , doc. 31 .

(66) R. MUNTANER, CCXLV, 886-7, op. cit, nota 33. J. M. DEL ESTAL, Conquista y anexión, op. cit., nota 17, pp. 154-5.

(67) R.A.H. Biblioteca Salazar, A, fol. 161. E. ABAD, El castillo de la Mola, op. cit., nota 38, pp. $77-81$.

(68) R.A.H. Biblioteca Salazar, A, 2, fol. 167: «...ordenamos e fazemos... a vos amado consejero e familiar nuestro don Gonzalo Garcia a recibir por nos e en nome e en lugar nuestro del muy noble e muy honrado don Fernando, rey de Castilla, e don Diego Garcia, su cancellero de/ siello de la puridat, o de qual quiere otra persona o personas por parte suya o del infante de Portugal don Alfonso e dona Violant su muger, los castiellos e lugares de Ella e de Novelda, los cuales deven ser livrados a nos segunt el arbitrio o sentencia dada entre dicho Rey de Castiella e nos". E. ABAD, ibid., p. 77.

(69) R.A.H. Biblioteca Salazar, A, 2, fol. 167. E. ABAD, ibid., p. 81.

(70) CODOIN AGCA, XXXIX, pp. 122, 113-115, 358-361. J. B. VILAR, Los siglos XIV-XV, op. cit., nota 1, pp. 51, 56, 251-252.

(71) A.C.A. Pergaminos de Pedro IV, lám. II.

(72) A.C.A. Reg. 235, fols. 222v. y 233. E. ABAD, El castillo de la Mola, op. cit., nota38, p. 83.

(73) A.C.A. Reg. 235, fols. 222 y 222v. E. ABAD, ver nota anterior.

(74) E. ABAD, El castillo de la Mola, op. cit., nota 38, p. 85. A. NAVARRO, Mistoria de Elda, op. cit., nota 18, p. 110.

(75) J. M. DEL ESTAL, Conquista y anexión..., op. cit., nota 17, p. 290.

(76) G. ROSSELLO-J. CAMPS, «Excavaciones arqueológicas en Palma de Mallorca. Sondeos practicados en la antigua Casa Desbrull», en N.A.H. Arqueologia, 2, 1973, pp. 131-166. G. ROSSELLO, Ensayo de sistematización de la cerámica árabe de Mallorca, Mallorca, 1978. R. AZUAR, «Panorama de la arqueología medieval», op. cit., nota 1, p. 366.

(77) C. CASTAN-J. R. CAYON, Las monedas hispano-musulmanas y cristianas, Madrid, 1980, p. 85. P. A. LILLO-J. A. MELGARES, "El tesorillo de dirhemes almohades de Cehegin (Murcia)», en Miscelánia Medieval Murciana, Universidad de Murcia, 1983, p. 15.

(78) C. CASTAN-J. R. CAYON, Las monedas..., op. cit., nota 77, pp. 56-58. P. A. LILLO-J. A MELGARES, “El tesorillo de dirhemes...", op. cit., nota 77, p. 13.

(79) R. AZUAR, «Panorama de la arqueología medieval...", op. cit., nota 1, p. 366.

(80) R. AZUAR, ver cita anterior.

(81) A. M. POVEDA, “La ciudad romana de Elo...", op. cit., nota 2.

(82) Ver nota 2.

(83) R. AZUAR, Castellologia Medieval, op. cit., nota 1, pp. 109-110.

(84) J. A. GISBERT, “La cerámica vidriada con decoración estampillada en la Denia islámica", en III J.C.A.I., sp. Noticia oral de J. M. Soler Garcia, a quien agradecemos que nos mostrase las estampillas vidriadas hailadas en Viliena.

(86) G. ROSSELLO, Ensayo de sistematización..., op. cit., nota 76. R. AZUAR, «Panorama de la arqueología medieval...", op. cit., nota 1, p. 367.

(87) Centro Excursionista Eldense, "Carta Arqueológica del valle de Elda", en A.P.L., XIII, Valencia, 1972, p. 203.

(88) R. AZUAR, «Panorama de la arqueología...», op. cit., nota 1, p. 367. 